\title{
The metabolism and availability of essential fatty acids in animal and human tissues
}

\author{
J Bézard ${ }^{1}$, JP Blond ${ }^{1}$, A Bernard ${ }^{2}, \mathrm{P}$ Clouet ${ }^{1}$ \\ 1 Nutrition Cellulaire et Métabolique (EA DRED 564), Université de Bourgogne, \\ BP 138, 21004 Dijon Cedex; \\ 2 Département de Nutrition (EA DRED 580), ENS BANA, 21000 Dijon, France
}

\begin{abstract}
Summary - Essential fatty acids (EFA), which are not synthesized in animal and human tissues, belong to the $n-6$ and $n-3$ families of polyunsaturated fatty acids (PUFA), derived from linoleic acid (LA, 18:2n-6) and $\alpha$-linolenic acid (LNA, 18:3n-3). Optimal requirements are $3-6 \%$ of ingested energy for LA and $0.5-1 \%$ for LNA in adults. Requirements in LNA are higher in development. Dietary sources of LA and LNA are principally plants, while arachidonic acid (AA, 20:4n-6) is found in products from terrestrian animals, and eicosapentaenoic acid (EPA) and docosahexaenoic acid (DHA) are found in products from marine animals. EFA are principally present in dietary triacylglycerols, which should be hydrolyzed by lipases in gastric and intestinal lumen. DHA seems to be released more slowly than the others. Its intestinal absorption is delayed but not decreased. Long-chain PUFAs are incorporated in noticeable amounts in chylomicron phospholipids. However, their uptake by tissues is no more rapid than uptake of shorter chain PUFA. In tissues, LA and LNA, which constitute the major part of dietary EFA, should be converted into fatty acids of longer and more unsaturated chain by alternate desaturation $(\Delta 6, \Delta 5, \Delta 4)$-elongation reactions. Animal tissues are more active in this biosynthesis than human tissues. Liver is one of the most active organs and its role is critical in providing less active tissues, particularly the brain, with long-chain PUFA secreted in VLDL (very low density lipoprotein). In liver, many nutritional, hormonal and physiological factors act on the PUFA biosynthesis. Dietary fatty acids exert a great influence and are often inhibitory. Dietary LNA inhibits $\triangle 6$ desaturation of LA. The desaturation products AA, EPA, and DHA inhibit $\Delta 6$ desaturation of $L A$ and $\Delta 5$ desaturation of DGLA (dihomo- $\gamma$-linolenic acid). With regard to hormones, insulin and thyroxin are necessary to $\Delta 6$ and $\Delta 5$ desaturation activities, whereas other hormones (glucagon, epinephrine, ACTH, glucocorticoids) inhibit desaturation. Concerning the physiological factors, the age of individuals is critical. In the fetus, the liver and the brain are capable of converting LA and LNA into longer-chain EFA, but these are also delivered by the mother, after synthesis in the maternal liver and placenta. Just after birth, in animals, the $\Delta 6$ desaturation activity increases in the liver and decreases in the brain. In aging, the capacity of the whole liver to desaturate LA and DGLA is equal at 1.5 and 25 months of age in rats fed a balanced diet throughout their life and the AA and DHA content of tissue phospholipids is unchanged in aging. Fatty acid oxidation in the liver is also likely to decrease the availability of EFA in tissues, in
\end{abstract}


particular oxidation of long-chain PUFAs which is high in peroxisomes. However, in healthy individuals, despite the numerous factors likely to influence the availability of EFA, in most cases a regular and balanced diet meets the tissue requirements in n-6 and n-3 EFA

essential fatty acids / dietary sources / desaturation / oxidation / nutritional factors / hormonal factors / physiological factors

Résumé - Métabolisme et disponibilité des acides gras indispensables dans les tissus animaux et humains. Les acides gras indispensables (EFA), qui ne sont pas synthétisés dans les tissus animaux et humains, appartiennent aux 2 familles d'acides gras polyinsaturés (PUFA) n-6 et $n-3$, dérivant de l'acide linoléique ( $L A, 18: 2 n-6)$ et de l'acide $\alpha$-linolénique ( $L N A, 18: 3 n$-3). Les besoins optima sont de 3-6\% de l'énergie ingérée pour $L A$ et de $0,5-1 \%$ pour $L N A$ chez les adultes. Les besoins en $L N A$ sont supérieurs au cours du développement. Les sources alimentaires de $L A$ et de $L N A$ sont principalement végétales, tandis que l'acide arachidonique $(A A, 20: 4 n-6)$ est présent dans les produits des animaux terrestres et les acides eicosapentaénoïque (EPA) et docosahexaénoïque (DHA) sont présents dans les produits des animaux marins. Ces acides gras sont présents principalement dans les triacylglycérols, qui doivent être hydrolysés par des lipases dans la lumière gastrique et intestinale. Le DHA paraît libéré plus lentement que les autres. Son absorption intestinale est retardée mais non diminuée. Les PUFA à longue chaîne sont incorporés dans les phospholipides des chylomicrons en proportion notable. Toutefois, ils ne sont pas captés par les tissus plus rapidement que les PUFA plus courts. Dans les tissus, $L A$ et $L N A$, qui constituent la majeure partie des EFA fournis par l'alimentation, doivent être convertis en acides gras à plus longue chaîne et plus insaturés par une série alternée de désaturations ( $\Delta 6, \Delta 5$ et $\Delta 4$ désaturations) et d'élongations. Dans cette biosynthèse, les tissus animaux sont plus actifs que les tissus humains. Le foie est un des organes les plus actifs et son rôle est primordial pour l'approvisionnement des autres organes moins actifs, comme le cerveau, en PUFA à longue chaîne sécrétés avec les VLDL (very low density lipoprotein). Dans le foie, de nombreux facteurs nutritionnels, hormonaux et physiologiques interviennent sur la biosynthèse des PUFA. Les acides gras du régime ont une grande influence et sont souvent inhibiteurs. Ainsi $L N A$ alimentaire inhibe la $\triangle 6$ désaturation de $L A$. De même, $A A, E P A$ et $D H A$, produits des désaturations, inhibent la $\triangle 6$ désaturation de $L A$ et la $\triangle 5$ désaturation de DGLA (dihomo- $\gamma$-linolénique). Parmi les hormones, l'insuline et la thyroxine sont nécessaires à l'activité des $\Delta 6$ et $\Delta 5$ désaturation tandis que d'autres hormones (glucagon, adrénaline, ACTH, glucocorticoïdes) les inhibent. Concernant les facteurs physiologiques, l'âge est un facteur important. Chez le fotus, le foie et le cerveau sont capables de convertir LA et LNA en EFA plus longs mais ceux-ci sont aussi apportés par la mère, synthétisés dans le foie et le placenta maternels. Juste après la naissance, chez l'animal, l'activité de $\Delta 6$ désaturation augmente dans le foie et diminue dans le cerveau. Au cours du vieillissement, les capacités du foie entier à désaturer LA et DGLA sont les mêmes à 1,5 et 24 mois chez le rat recevant un régime équilibré toute sa vie, et les contenus en AA et DHA des phospholipides tissulaires ne sont pas modifiés avec l'âge. L'oxydation des acides gras dans le foie peut aussi diminuer la disponibilité en EFA dans les tissus en particulier l'oxydation des PUFA à longue chaîne qui est élevée dans les peroxisomes. Toutefois, chez les individus sains, en dépit des nombreux facteurs susceptibles d'influencer la biodisponibilité en EFA, un régime régulier et équilibré permet, dans la plupart des cas, de satisfaire les besoins des tissus en EFA n-6 et n-3.

acides gras indispensables / sources alimentaires / désaturations / oxydation / facteurs nutritionnels, hormonaux et physiologiques

\section{INTRODUCTION}

The properties of lipids are those of their component fatty acids. These can be divided, according to their chemical structure, into 2 broad groups: saturated and unsaturated fatty acids. The latter can then be further sub-divided, according to their biological properties, into 2 different narrower groups: mono- and polyunsaturated fatty acids (PUFA). The latter group is composed of 4 families of fatty acids. The first 2 
are the palmitoleic ( $\mathrm{n}-7)$ and oleic $(\mathrm{n}-9)$ families which are not essential since they are synthesized de novo in most cells. On the contrary, the next 2 families, namely the linoleic ( $n-6)$ and linolenic (n-3) families, cannot be synthesized de novo by animal cells and hence must be provided in the diet. All the members of these 2 independent families derive from their respective precursors, linolenic acid (LA, 18:2n-6) and $\alpha$-linolenic acid (LNA, 18:3n-3) by alternate desaturation-elongation reactions (fig 1) (Sprecher, 1981).
In the absence of these dietary unsaturated $n-6$ and $n-3$ fatty acids, growth, learning, visual activity are impaired in rats and severe structural and metabolic disorders take place (Burr and Burr, 1929; Holman, 1970; Neuringer et al, 1988; Vergroesen and Crawford, 1989). These perturbations underline the important functions of essential fatty acids (EFA). Indeed EFA are important in membrane structure as major components of phospholipids for the integrity and fluidity of intracellular and plasma mem.
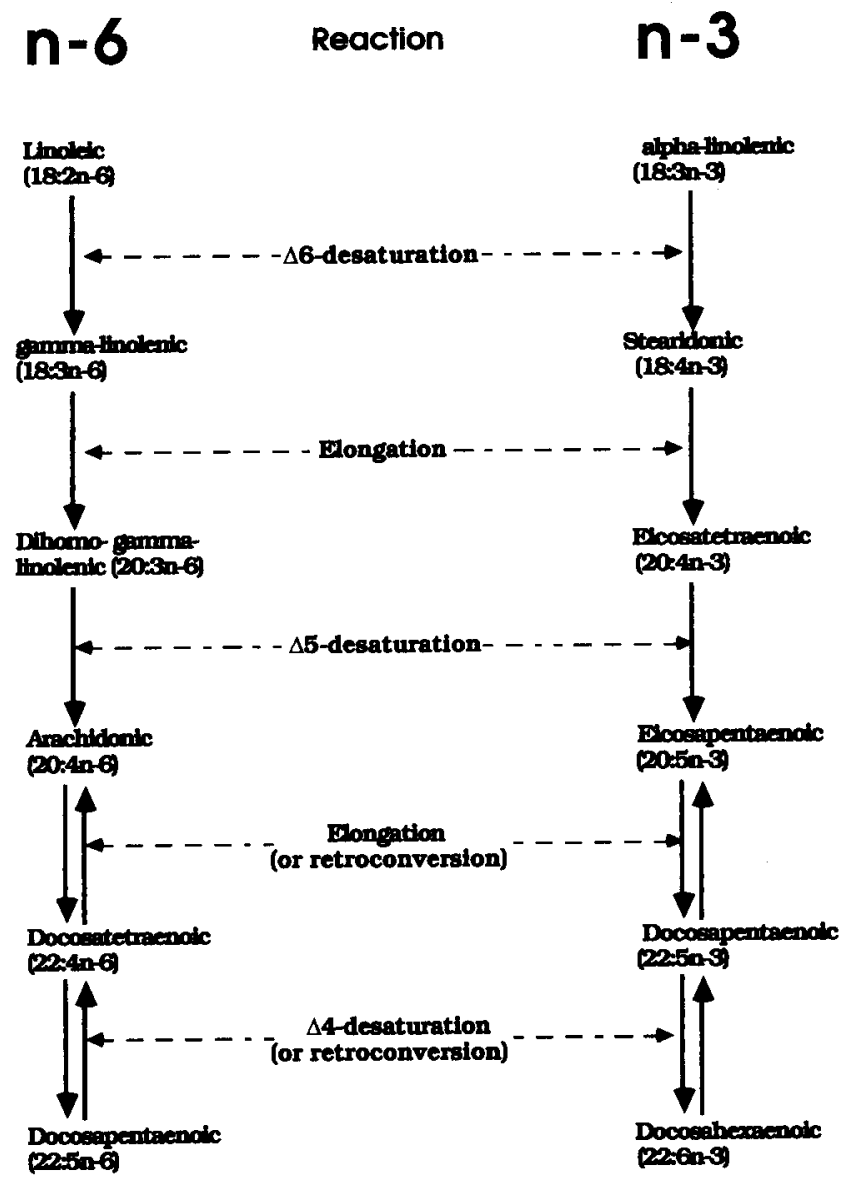

Fig 1. Outline of the more common pathways by which unsaturated fatty acids of the $n-6$ (linoleic) and $\mathrm{n}-3$ (linolenic) families are converted to long-chain polyunsaturated fatty acids in animal tissues. 
branes (Kinsella, 1991). In this regard, they modulate activity of membrane-bound receptors, enzymes, molecule carriers and ionic channels. In addition, several of them, namely dihomo- $\gamma$ linolenic (DGLA, 20:3n-6), arachidonic (AA, 20:4n-6) and eicosapentaenoic (EPA, 20:5n-3) acids can be easily converted into a wide range of eicosanoids including prostanoids (prostaglandins), thromboxanes, prostacyclines and leukotrienes. These have potent biological effects regulating such important physiological functions as reproduction, heart and vascular physiology and immune functions (Curtis-Prior, 1988). Finally, n-6 fatty acids are often associated with cholesterol in plasma (18:2 and/or 20:4n-6) and in adrenals (adrenic acid, 22:4n-6) thereby participating in the normal intravascular and cellular metabolism of this key molecule.

To help their important structural and biological functions, EFA must be provided to tissues in appropriate and equilibrated amounts. Many factors are likely to affect their availability. Their dietary intake is one of the most critical.

\section{REQUIREMENTS IN ESSENTIAL FATTY ACIDS}

Recommended dietary intakes of essential fatty acids are not easy to be proposed, since optimal requirements are not fully known. However, some information is available (Lemarchal et al, 1992).

In the $n-6$ family, LA is the major essential fatty acid and no more than $1-2 \%$ of calories is required to relieve symptoms of essential fatty acid deficiency in rats (Kinsella, 1991). But to ensure at best the biological functions of essential fatty acids, intake of $3-6 \%$ is generally recommended. Higher amounts have sometimes been proposed in adults, since LA is beneficial in reducing $L D L$-cholesterol, atherosclerosis and coronary heart disease. But recent results are indicative of a positive relationship between LA intake and coronary heart disease (Hodgson et al, 1993). It seems prudent, therefore, not to promote increased consumption of this essential fatty acid. An intake of 7-10 g LA per day seems reasonable. On the other hand, intake of AA probably decreases the need for $L A$, but the optimum ratio between these 2 essential $n-6$ fatty acids is not known.

LNA, the precursor of EPA and docosahexaenoic acids (DHA) is also required, especially in the diet of pregnant women and nursing mothers as a source of DHA for neural and visual tissues during development of the embryo and neonate (Kinsella, 1991). From results of different authors (Holman et al, 1982; Bjerve et al, 1987; Bourre et al, 1989; Guesnet et al, 1993), the optimal requirement for LNA could be $0.5-1 \%$ of calories, while requirements for EPA and DHA would be $0.4 \%$. According to Bjerve et al (1989), the optimal intake of LNA would be 860 to $990 \mathrm{mg}$ per day, and 350-400 mg for EPA and DHA. The optimal balance between EPA and DHA was not proposed by these authors.

Since DHA is a major fatty acid component of the grey matter of the cerebral cortex and of the photoreceptor membranes of the rod outer segment of the retina and since deprivation of LNA has been associated with impaired learning and visual activity (Neuringer et al, 1988), the need for $n-3$ essential fatty acids has been estimated to be higher in the early stages of life, to ensure optimum development and function of neural and visual tissues, ie $0.7-1.2 \%$ of calories according to Lemarchal et al (1992).

A general agreement is that intake of $\mathrm{n}-6$ and $\mathrm{n}-3$ essential fatty acids ranging from 4:1 to $6: 1$ is prudent (Neuringer et al, 1988). Most human milks analyzed contain around $1-2 \% n-3$ fatty acids and the $n-6 / n-3$ fatty acid ratio is within the range suggested. It may reflect the need of the neonate for opti- 
mal growth, depending on tissue AA content (Carlson et al, 1992) and optimal neural and visual development, depending on tissue DHA content (Uauy et al, 1992).

\section{DIETARY SOURCES OF ESSENTIAL FATTY ACIDS}

As already mentioned, since they cannot be synthesized de novo, n-6 and n-3 polyunsaturated fatty acids must be provided in the diet. Plants are the principal sources of these fatty acids. Unlike animals, plants possess the capacity to insert double bonds between the existing $n-9$ double bond and the methyl end of oleic acid (Demandre et al, 1986). Edible vegetable oils, such as sunflower, corn or peanut oil, constitute a major source of LA (Kinsella, 1991). Table I shows that $65 \%$ of the sunflower oil fatty acids are LA. The amount is still higher in safflower oil (75-80\%). In addition, several oils provide LNA, soybean oil ( $8 \%)$, low-erucic acid rapeseed oil $(9 \%)$ and walnut oil $(13 \%)$. The chloroplast membranes of green leafy plants are very rich in LNA but the total amount of the acid provided by these foods is modest since they do not contain large amounts of lipids (Kinsella, 1991). Animal feeds generally contain low amounts of LA. Human milk supplies the neonate with a relatively high quantity of LA (10-13\%) (Martin et al, 1993). On the contrary, bovine milk and the dairy products are poor sources of essential fatty acids (Maniongui et al, 1991). Longer-chain essential n-6 and n-3 fatty acids are generally provided in food from animal sources, ie liver, kidneys, eggs, whereas marine foods are good sources of EPA and DHA (n-3). Fresh water fish contains both $n-6$ and $n-3$ very long-chain fatty acids (Kinkela and Bézard, 1993). Human milk also provides the neonate with very long-chain essential $n-6$ and $n-3$ fatty acids (Martin et al, 1993). Several vegetable oils contain essential fatty acids located beyond the rate-limiting $\Delta 6$ desaturation step. Evening primrose, borage and blackcurrant oils contain significant amount of $\gamma$-linolenic acid (GLA, 18:3n-6).

Table I. Examples of n-6 and n-3 essential fatty-acid concentration (mol \%) in lipids of some animal products and edible oils.

$\begin{array}{llll}18: 2 n-6 & 18: 3 n-3 \quad 20: 4 n-6 \quad 20: 5 n-3 \quad 22: 6 n-3\end{array}$

\begin{tabular}{|c|c|c|c|c|c|}
\hline Human milka & 12.7 & 0.6 & $1.0^{\mathrm{b}}$ & & $0.4^{\mathrm{b}}$ \\
\hline Bovine milkc & 1.9 & 0.8 & & & \\
\hline Beef fat ${ }^{d}$ & 5 & 1 & & & \\
\hline Pork fate & 6 & 2 & & & \\
\hline Pork liver (TAGf)e & 17 & 1 & 4 & 1 & 1 \\
\hline Egg yolk (TAG')g & 10 & 0.6 & & & \\
\hline Egg yolk $\left(P L^{f}\right)^{h}$ & 16 & 0.1 & 3.8 & & 1.9 \\
\hline Sunflower oili & 65 & 0.2 & & & \\
\hline Peanut oilj & 33 & 0.1 & & & \\
\hline Rapeseed oili & 22 & 9 & & & \\
\hline Walnut oili & 59 & 13 & & & \\
\hline Sea fishi & 2 & 1 & 1 & 12 & 39 \\
\hline Fresh-water fishi & 8 & 2 & 9 & 8 & 13 \\
\hline
\end{tabular}

a Martin et al, 1993; b $\Sigma n-6$ and $\Sigma n-3$ very-long-chain fatty acids; c Maniongui et al, 1991; d Brockerhoff et al, 1966; ${ }^{\ominus}$ Christie and Moore, $1970 a ;{ }^{f}$ TAG $=$ triacylglycerols, $\mathrm{PL}=$ phospholipids; 9 Christie and Moore, $1970 b ;{ }^{h}$ Kuksis and Marai, 1967; ' Commercial samples, personal analyses, unpublished data; i Kinkela and Bézard, 1993. 
Blackcurrant oil also contains stearidonic acid (18:4n-3) (Lawson and Hughes, 1988a).

From the above data, it is evident that a varied diet in sufficient amounts can easily provide $n-6$ and $n-3$ essential fatty acids in suitable amounts. However, the dietary fatty acids must first cross the intestinal epithelium before they can reach the different tissues. Digestion and absorption of dietary lipids constitute further factors that can influence availability of EFA.

\section{DIGESTION AND INTESTINAL ABSORP. TION OF ESSENTIAL FATTY ACIDS}

A recent report (Carlier et al, 1991) dealt with the question of digestion and absorption of EFA. A previous review (Nelson and Ackman, 1988) had been principally concerned with n-3 PUFA.

Dietary fatty acids are mainly present in triacylglycerols (> 95\%). The others are provided by phospholipids and cholesteryl esters, the dietary intake of which is important since they contain high proportion of very long-chain EFAs.

The processes of lipid digestion and absorption have been reviewed several times in the last few years (Bézard and Bugaut, 1986; Bernard and Carlier, 1989; Thomson et al, 1989; Carlier et al, 1991).

With regard to PUFA, 2 peculiarities have to be considered, ie their structure which determines their chemical and biological properties and their position in dietary triacylglycerol and phospholipid molecules.

Concerning the structure of $n-3$ polyunsaturated fatty acids, several authors (Brockerhoff and Yurkowski, 1966; Bottino et al, 1967) have observed that certain long-chain PUFA of marine oils were resistant in vitro to pancreatic lipase hydrolysis. This was attributed to the presence of a double bond between carbon 2 and carbon 5 of the acyl chain (when counted from the carboxylic end). This is the case with DHA, in which the first double bond is located at the 4th carbon atom. The resistance to lipolysis seemed independent of the position of fatty acid in the glycerol moiety of triacylglycerol. This property could impair absorption of DHA from marine oils when transposed in vivo. However, this point is very controversial and many studies in vivo gave conflicting results (Carlier et al, 1991). It seems that absorption could be delayed but not decreased, so that availability would not be affected. Nevertheless further investigations are required to answer this question.

Another problem is the digestion of EPA and DHA when supplemented as ethyl esters (instead of natural glyceryl esters). Their absorption is impaired (Lawson and Hughes, 1988b). However, hydrolysis takes place, probably less rapidly but completely. The absorption could be impaired because of lack of the 2 monoacyl-sn-glycerols necessary for triacylglycerol resynthesis in enterocytes. Indeed absorption was considerably increased when ethyl esters were accompanied by dietary triacylglycerols (Lawson and Hughes, 1988c; Yang et al, 1989).

The position of fatty acids in the triacylglycerol molecules is another factor affecting their hydrolysis and absorption. Triacylglycerols are partially hydrolysed in the stomach in man in the presence of a gastric lipase. It preferentially hydrolyzes fatty acids in the external sn- 1 and sn-3 positions, with the sn-3 more rapidly cleaved than the sn- 1 position (Ransac et al, 1990, Rogalska et al, 1990). Lipolysis continues in the small intestine catalyzed by pancreatic lipase which splits off fatty acids in sn- 1 and sn-3 positions at equal rate. The 2 monoacyl-sn-glycerols formed are rapidly absorbed, while the liberated fatty acids are likely to form insoluble calcium soaps and to be absorbed to a lower extent. This underlines the importance of the EFA position in dietary triacylglycerols.

The data in table II confirm the wellknown preferential esterification of $L A$ in 
sn-2 position in vegetable oils (Litchfield, 1972) and even in pork liver triacylglycerols, whereas it is not true in depot fats (Christie and Moore, 1970b). In humans, the coefficient of digestibility of the most common vegetable oils in $97-98 \%$. Only hydrogenated oils, comprising high amounts of saturated and isomeric fatty acids, have lower coefficients (Deuel, 1955). In these conditions, LA can be considered as totally absorbed. Contrary to LA, LNA is preferentially esterified in external positions in soybean oil triacylglycerols (table II). However, its absorption is probably total since the coefficient of digestibility of soybean oil was found to be $97 \%$ in humans, and $98 \%$ in rats (Deuel, 1955). EPA and DHA are much more often found in sn-2 position in herring oil (table II) as in other fish oils (Brockerhoff et al, 1968). The only problem is the possible resistance of DHA to lipoly- sis, not its location in fish oil triacylglycerols.

How and to what extent are fish-oil fatty acids absorbed in the small intestine? Conflicting results were obtained as for the amount absorbed (Carlier et al, 1991). According to results obtained on rats fed $0.5 \mathrm{ml}$ corn oil, menhaden oil or cod liver oil, no difference was observed between oils concerning the amount absorbed (Carlier et al, 1991). The only difference was that cod liver oil absorption was delayed, since peak absorption occurred at $5 \mathrm{~h}$ instead of $2-3 \mathrm{~h}$ for the other 2 oils. The difference could be accounted for by the higher content in DHA of cod liver oil, when compared to menhaden oil, while the reverse was true for EPA. Other differences in fatty acid composition also exist between the 2 fish oils, which could also explain the different absorption profiles.

Table II. Distribution of fatty acids between the 3 positions of the glycerol moiety of triacylglycerols from several foods.

\begin{tabular}{|c|c|c|c|c|c|c|}
\hline & Position a & $18: 2 n-6$ & $18: 3 n-3$ & $20: 4 n-6$ & $20: 5 n-3$ & $22: 6 n-3$ \\
\hline Peanut oilb & $\begin{array}{l}1,2,3 \\
1 \\
2 \\
3\end{array}$ & $\begin{array}{l}32 \\
32 \\
56 \\
12\end{array}$ & & & & \\
\hline Soybean oilc & $\begin{array}{l}1,2,3 \\
1 \\
2 \\
3\end{array}$ & $\begin{array}{l}54 \\
29 \\
43 \\
28\end{array}$ & $\begin{array}{r}8 \\
38 \\
29 \\
33\end{array}$ & & & \\
\hline Pork liverd & $\begin{array}{l}1,2,3 \\
1 \\
2 \\
3\end{array}$ & $\begin{array}{l}17 \\
14 \\
48 \\
38\end{array}$ & & $\begin{array}{r}4 \\
13 \\
31 \\
55\end{array}$ & & \\
\hline Herring oile & $\begin{array}{l}1,2,3 \\
1 \\
2 \\
3\end{array}$ & $\begin{array}{r}2 \\
43 \\
43 \\
14\end{array}$ & & & $\begin{array}{r}8 \\
12 \\
72 \\
16\end{array}$ & $\begin{array}{r}5 \\
7 \\
86 \\
7\end{array}$ \\
\hline
\end{tabular}

a 1, 2, 3: percentage of fatty acid in total triacylglycerols; 1-2-3: percentage of fatty acid in the 3 positions (total = 100); b Sempore and Bézard, 1991; ${ }^{c}$ Yurkowski and Brockerhoff, 1966; d Christie and Moore, †970a; ${ }^{\text {e }}$ Brockerhoff et al, 1968. 
An interesting observation by several authors (Chen et al, 1985; Carlier et al, 1991 ) is the higher recovery of PUFA in phospholipids in comparison with oleic acid. In rats, $18 \%$ of $20: 4 n-6$ was incorporated into lymph phospholipids, instead of $3 \%$ of oleic acid in the 3rd half-hour following absorption of the free fatty acids in rats (Carlier et al, 1991). Several explanations can be provided. Because of selectivity of acyltransferases, generally AA, EPA and DHA are rapidly and selectively of acylated into phospholipids (Kinsella, 1991). Secondly, the L-FABP (liver-fatty acid binding protein) present in enterocytes, contrary to the 1FABP (intestinal-FABP), might exhibit higher affinity for PUFA than for others (Lowe et al, 1987) and might thus channel these acids to phospholipid synthesis.

Dietary phospholipids are hydrolyzed in the presence of pancreatic phospholipase A2 which splits off the fatty acids esterified in the sn-2 position. The cholesterol ester hydrolase hydrolyzes cholesteryl esters. The hydrolysis products together with those derived from triacylglycerols are utilized in the enterocytes to form chylomicrons, which are secreted in the lymph.

Besides their function of transferring fatty acids from the intestinal lumen to the lymph, enterocytes can also metabolize EFA. Bernard et al (1991) have shown that, when rats were fed diets containing $\left(1-{ }^{14} \mathrm{C}\right) \mathrm{LA}$, $4-7 \%$ of the radioactivity recovered in lymph lipids was present in AA. Caselli et al (1993) have further demonstrated that the intestine was itself able to synthesize and secrete AA from dietary $L A$.

\section{UPTAKE OF ESSENTIAL FATTY ACIDS BY TISSUES}

The absorbed EFA are taken up by tissues. Although PUFA are recovered in phospholipids in relatively high proportion, it does not seem that they are taken up at higher or lower rates than others, as observed by Chen et al (1987). The authors injected recipient rats with lymph chylomicrons containing triglycerides enriched with labelled oleic acid or eicosapentaenoic acid (EPA). During the early stages of uptake, they observed no difference between the disappearance rates of both types of chylomicrons. However, after longer time periods, clearance of EPA-enriched chylomicrons was slightly lower.

Results dealing with the uptake by the different tissues or organs of essential PUFA esterified in triacylglycerols, phospholipids or cholesteryl esters are not abundant. On the contrary, because of easier interpretation, experiments with non-esterified fatty acids are more numerous. For example, Anderson and Connor (1988) have studied the uptake of free labelled fatty acids bound to albumin by the developing brain of 15-dayold rats, in comparison with liver. They observed a steady and significant increase in uptake of labelled fatty acid in the brain as the degree of unsaturation increased. DHA $(22: 6 n-3)$ showed more than twice as much uptake as palmitic acid (16:0) and considerably more than LA $(18: 2 n-6)$. The liver showed an even stronger preference for $22: 6 n-3$ than the brain, with the liver accumulating 4 times more radioactivity from this fatty acid than for the other 4 fatty acids tested, which were very similar in the uptakes. Expressed per gram of wet tissue uptake of $22: 6 n-3$ by the liver was 65 -fold higher than by the brain.

\section{AVAILABILITY OF ESSENTIAL FATTY ACIDS IN TISSUES}

The essential fatty acids used by animal cells to incorporate into their membrane phospholipids are most often long-chain PUFA, for example, AA (20:4n-6) and DHA $(22: 6 n-3)$. The C20 polyunsaturated fatty 
acids (20:3n-6, 20:4n-6 and 20:5n-3) are used to synthesize eicosanoids. In cells or in plasma, cholesterol is frequently associated with n-6 PUFA (20:4n-6, 22:4n-6) to form cholesteryl esters. However, diet provides essential fatty acids principally as LA and LNA. In tissue, these precursors should be converted into longer and more unsaturated fatty acids.

The conversion of the 2 precursors requires an alternating sequence of chain desaturation ( $\Delta 6, \Delta 5$ and $\Delta 4$ desaturations) and elongation reactions (fig 1) (Sprecher, 1981). These reactions, which occur principally on endoplasmic reticulum membranes (Brenner, 1989), require activated acyl-CoA esters. The activation is rapid and not rate limiting (Naughton, 1981). Desaturation introduces a double bond proximal to the carboxyl group, so that the molecules successively formed retain the position of the first double-bond in relation to the methyl end of the carbon chain, hence the ' $n$ ' (or $\omega)$ designation. The first desaturation step in the biosynthesis of longer chain polyenic fatty acids is $\Delta 6$-desaturation, effected by the enzyme $\Delta 6$-desaturase. The same enzyme converts LA to GLA and at a higher rate LNA to stearidonic acid. It is the rate-limiting reaction in the synthesis of $A A$ and EPA (Marcel et al, 1968). Since both LA and LNA are substrates of the same enzyme, competition occurs between the essential 2 fatty acids (Sprecher, 1989). Too high an amount of LNA in the diet can decrease conversion of LA into higher polyunsaturated $n-6$ fatty acids. Conversely too high an intake of LA is likely to impair synthesis of EPA and DHA from LNA. An appropriate dietary $n-6 / n-3$ fatty acid ratio is therefore critical.

A second enzyme, the $\Delta 5$-desaturase, converts dihomo- $\gamma$-linolenic acid (DGLA) to arachidonic acid (AA). Both fatty acids, substrate and product, are precursors of eicosanoids of families 1 and 2 . Activity of the $\Delta 5$-desaturase activity, regulates the availability of each precursor. $\Delta 5$-desaturase also converts $20: 4 n-3$ to 20:5n-3 (EPA), the precursor of the 3rd family of eicosanoids. This shows the importance of the $\Delta 5$-desaturation step. The $\Delta 5$-desaturase, under certain circumstances, may be a rate-limiting enzyme (Bernert and Sprecher, 1975).

The $\Delta 4$-desaturation step necessary to form $22: 6 n-3$ may not require a specific $\Delta 4$ desaturase enzyme. Voss et al (1991) have shown that conversion of $22: 5 n-3$ to $22: 6 n$ 3 involved not one but 3 reactions, namely elongation followed by $\Delta 6$-desaturation in microsomes, and a peroxisomal shortening according to the scheme:

$$
\begin{gathered}
22: 5 n-3 \rightarrow 24: 5 n-3 \rightarrow 24: 6 n-3 \rightarrow \\
22: 6 n-3
\end{gathered}
$$

This revised pathway for 22:6n-3 biosynthesis has also recently been evidenced by Geiger et al (1993) for the n-6 family, according to the scheme:

$$
\begin{gathered}
22: 4 n-6 \rightarrow 24: 4 n-6 \rightarrow 24: 5 n-6 \rightarrow \\
22: 5 n-6
\end{gathered}
$$

Cook et al (1991) have described an alternative pathway of $18: 3 n-3$ conversion into 20:5n-3 observed in rat glioma cells. Though controversial, the synthesis would involve an elongation step followed by 2 desaturation steps, $\Delta 5$ - and $\Delta 8$-desaturation. $\Delta 6$-desaturase would not be implicated in this pathway.

Hagve and Christophersen (1986) have shown in isolated liver cells that adrenic acid (22:4n-6) and docosahexaenoic acid (22:6n-3) can be shortened by peroxisomal $\beta$-oxidation and that this reaction can be used to retroconvert the products to arachidonic acid (20:4n-6) and eicosapentaenoic acid (20:5n-3), respectively. By this means, a relatively high amount of $22: 6 n$ 3 in phospholipids can generate $20: 5 n-3$ in low amounts, for biosynthesis of the third series of prostanoids. 
Biosynthesis of longer chain polyenic fatty acids also proceeds through elongation steps resulting in addition of a 2-carbon unit to the acyl chain proximal to the carboxyl group (Sprecher, 1981). Apparently elongation reactions are not ratelimiting (Bernert and Sprecher, 1975). Elongation and desaturation of 20:4n-6 and $20: 5 n-3$ principally take place in endoplasmic reticulum. However, some transformations were observed to occur in peroxisomes (Mimouni et al, 1991).

The capacity of tissues or organs to synthesize $n-6$ and $n-3$ long-chain PUFA from LA and LNA, respectively, depends on the presence of active desaturase and elongase enzymes. The relative activity of these enzymes determine the relative amounts of products formed. Brenner (1971) showed that desaturation activity is not evenly distributed in all the organs. He studied the conversion of LA to GLA by $\triangle 6$-desaturation in microsomes from different organs. If the activity in liver was taken as 100 , the activity found in different organs were: adrenals (142), testicles (45), heart (8), kidneys (12), and brain (14), while no activity was detectable in lung and epididymal fat. In adult mice, Bourre et al (1990) showed that $\Delta 6$ desaturation activity in brain was ca $6 \%$ that found in liver. Thus, important organs such as brain heart and kidney, greatly depend on the liver for the synthesis and supply of long-chain PUFA.

However, the liver is not the only organ to provide tissues with longer chain fatty acids synthesized from LA. As mentioned above, the small intestine can synthesize and secrete AA from LA (Caselli et al, 1993). Placenta may also transform LA to AA. This question will be discussed later. In the appreciation of desaturation activity, the age of animals should also be taken into account, since the activity was observed to vary considerably with aging and differently from an organ to another (Cook, 1991), as will be seen later.
However, despite some adaptations, in particular in the developing brain, organs generally greatly depend on the liver for providing their long-chain PUFA.

For this reason, factors influencing the synthesis of these long-chain fatty acids in the liver were extensively studied. These factors influence the desaturases themselves, which are the rate-limiting steps of the desaturase systems and not the other 2 associated proteins, NADH cytochrome $b_{5}$ reductase and cytochrome $b_{5}$ (Brenner, 1981).

For simplicity, the factors influencing desaturase activity may be classified into nutritional factors, hormonal factors and physiological factors such as age. But it is evident that these factors are not independent and, in some cases, the effects of nutritional factors are likely to be explained by modification of the hormonal status. The major effects are reported in tables III and IV. Further detailed information is available in previous reviews (Brenner, 1989; Lemarchal, 1989; Kinsella, 1991).

\section{Nutritional factors}

Among the nutritional factors, dietary fatty acids are probably the most important (table III). Generally, fat-free diets and those deficient in EFA result in a sharp increase in $\Delta 6$-desaturase activity in rat liver. Marcel et al (1968) observed that the $\Delta 6$-desaturase activity of liver microsomes from rats fed a fat-free diet (deficient in EFA) was 2-fold greater compared with the activity in microsomes from chow-fed rats. Castuma et al (1972) and Brenner et al (1981) observed the same effect but to a lesser extent. The effects of EFA deficiency on $\triangle 5$-desaturation activity are more controversial. De Gomez Dumm et al (1983) observed that the activity was decreased. However, contrary to this, several authors observed that 
Table III. Nutritional factors affecting $\Delta 6$ - and $\Delta 5$-desaturation in rat liver microsomes

\begin{tabular}{|c|c|c|}
\hline & $\Delta 6$ & $\Delta 5$ \\
\hline \multicolumn{3}{|l|}{ Dietary fatty acids } \\
\hline Essential fatty acid (EFA) deficiency & + & +- \\
\hline$\alpha$-Linolenic acid (18:3n-3) & - & + \\
\hline Eicosapentaenoic acid $(20: 5 n-3)$ and docosahexaenoic acid (22:6n-3) & - & - \\
\hline Linoleic acid $(18: 2 n-6)$ & + & + \\
\hline$\gamma$-Linolenic acid $(18: 3 n-6)$ & +- & 0 \\
\hline Arachidonic acid $(20: 4 n-6)$ & - & - \\
\hline Oleic acid $(18: 1 n-9)$ & - & \\
\hline Trans-fatty acids & -0 & +-0 \\
\hline Cyclopropenoic fatty acids & - & - \\
\hline \multicolumn{3}{|l|}{ Other factors } \\
\hline \multicolumn{3}{|l|}{ Cholesterol } \\
\hline In vitro & + & + \\
\hline In vivo & - & - \\
\hline \multicolumn{3}{|l|}{ Protein } \\
\hline Low intake & - & - \\
\hline High intake & + & + \\
\hline Glucose, fructose, glycerol & - & \\
\hline Ethanol & - & - \\
\hline Zinc deficiency & +0 & - \\
\hline High $\mathrm{NaCl}$ intake & +- & +- \\
\hline Fasting & - & +- \\
\hline Fasting + glucose refeeding & + & \\
\hline
\end{tabular}

the $\Delta 5$-desaturation was increased (Christiansen et al, 1969; Do and Sprecher, 1975). Blond and Bézard (1991) showed that in liver microsomes from rats fed a fat-free diet, the conversion of DGLA into AA by $\triangle 5$-desaturation was 3-fold higher after 15 min of incubation, compared with the activity of liver microsomes from rats fed a commercial diet. The increase in $\Delta 6$ - and $\Delta 5$-desaturation activity may reflect a response to ensure maximum synthesis of PUFA from 18:1n-9 (n-9 family) to maintain the fluidity of membranes. In this view, Brenner et al (1981) demonstrated that changes in fatty-acid composition of the microsomal membranes induced by a diet deficient in EFA did not alter the phase transition tem- perature of the lipids as determined by electron spin resonance.

The presence of certain fatty acids in the diet is also likely to modify either the activity of the $\Delta 6$ - or the $\Delta 5$-desaturase or the desaturation rate by competition. Sometimes both occur. The best example is the presence of LNA, substrate of the $\Delta 6$-desaturase and competitive inhibitor of LA desaturation. As early as 1964, Holman reported that LNA was by far the most potent inhibitor of $\Delta 6$ desaturase in the diet or in the incubation medium. When an increasing amount of LNA was added to rat liver homogenates, Blond and Lemarchal (1984) showed that $\Delta 6$-desaturation of LA was highly decreased 
while $\Delta 5$-desaturation of DGLA was also decreased but to a lesser extent. This was confirmed by observations in vivo by Bourre et al (1989). Garg et al (1988a) also observed in vivo that, when present in the diet, LNA contained in high amounts in linseed oil, also evoked inhibition (by $30 \%$ ) of $\Delta 6$-desaturation when compared to a control diet (beef tallow). On the contrary, the $\Delta 5$ desaturation rate was increased ( $x$ 1.5) (Garg et al, 1988a). However, in similar experiments, Choi et al (1989) and Christiansen et al (1991) showed that the $\Delta 6$ desaturase activity was increased $(+50 \%)$. The $\Delta 5$-desaturase activity was also increased (Christiansen et al, 1991) and to higher extent $(x 3.5)$ than was observed by Garg et al (1988b). These discrepancies probably originate from differences in the control diet. Garg et al (1988a,b) used beef tallow, rich in saturated fatty acids, as a control fat, but at the same amount as the experimental diet ( $20 \% \mathrm{wt})$, whereas Christiansen et al (1991) used a commercial diet containing $5 \%$ of lipids, compared to $20 \%$ of linseed oil in experimental diet. The amount of dietary lipids is likely to influence the desaturation rate as can the type of control fat. Indeed Kurata and Privett (1980) showed that the level of fat affected the composition of liver fatty acids. The AA content increased from 11 to $21 \%$ in rats consuming 5 and $20 \%$ coconut oil respectively for 33 weeks, apparently indicating that $\Delta 6$ - and $\Delta 5$-desaturases were stimulated by the high fat diet, although differences in AA utilisation may be also involved.

Results obtained with the long-chain n-3 fatty acids, EPA + DHA are less controversial. These acids found mainly in fish oils markedly depress $\Delta 6$-desaturase enzyme (Choi et al, 1989; Christiansen et al, 1991). They also depress $\Delta 5$-desaturase activity (Garg et al, 1988b). Figure 2 reports results obtained in our laboratory in obese and lean Zucker rats fed fish oil in the diet at very low concentration for 12 weeks. The $\Delta 6$-desat- uration rate was measured in liver microsomes with LA and LNA as substrates. The $\triangle 5$-desaturation rate was measured with DGLA as substrate. The results illustrated in figure 2 confirm what was previously demonstrated (Blond et al, 1989) that $\Delta 6-$ and $\Delta 5$ desaturase activities are lower in obese rats than in control lean rats, especially with the $n-6$ fatty acids as substrates. Additionally, the fish oil diet highly depressed the $\Delta 6$ desaturase activity but uniquely with LA as a substrate and to a higher extent in lean rats. The same was true with $\Delta 5$-desaturation of DGLA to AA. The depressed capacity of liver microsomes to synthesize AA from LA was reflected in the AA content of microsomal phospholipids which was decreased, while the DHA content was increased. Surprisingly in these experiments the AA content was not decreased in heart phospholipids of rats fed the fish oil diet. It was even increased in kidney phospholipids of obese rats, but not of lean rats. Since heart and kidney exhibit low capacity of desaturation, the unaltered fatty acid profile of the phospholipids of these organs could result from a preferential uptake of the long-chain EFA from the blood lipids.

Dietary $n-6$ fatty acids also alter desaturation rates. Periago et al (1989) observed in rats that feeding corn oil, containing nearly $60 \% 18: 2 n-6$, increased the $\Delta 6$-desaturation rate by more than 2 fold when compared to olive oil containing $72 \% 18: 1 n-9$. With sunflower oil $(32 \% 18: 2 n-6)$ in the diet, Christiansen et al (1991) observed the same extent of increase of $\Delta 6$-desaturation rate. In addition, the authors showed a 2.5-fold increase in $\Delta 5$-desaturation rate. These results are very similar to what was observed with dietary LNA.

GLA (18:3n-6), the product of $\Delta 6$-desaturation of $L A(18: 2 n-6)$, is present in evening primrose, borage and blackcurrant seed oils. When added to the diet, they modify $\Delta 6$ - and $\Delta 5$-desaturation rates, the effect depending on age, strain of rats and type 


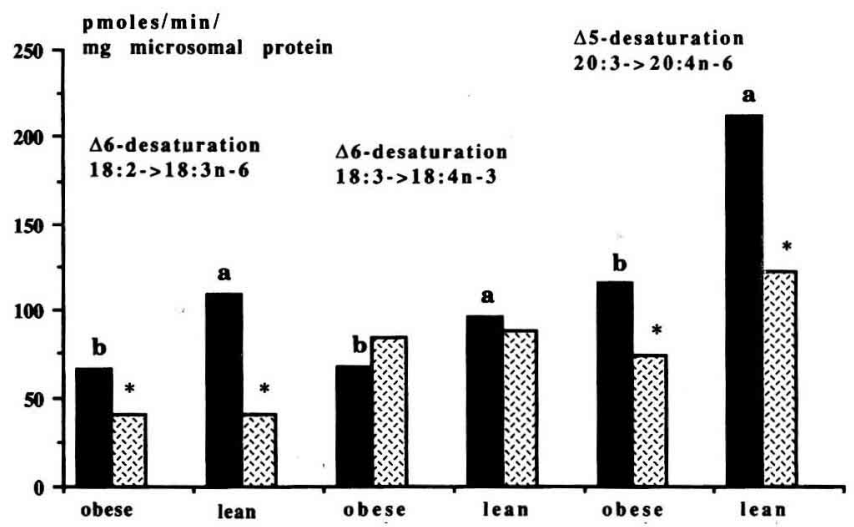

Fig 2. $\Delta 6$ - and $\Delta 5$-desaturation of $n-6$ and $n-3$ essential fatty acids in liver microsomes from obese and lean Zucker rats fed a fish-oil diet (FO) compared to control (CO). $\square$ Control rats (CO); $\square$ fish-oil fed rats $(F O)$; ${ }^{*} P<0.05$ : FO versus $C O$ in each phenotype; $a, b P<0.05$ : obese versus lean rats fed the control diet.

of GLA supplementation. Høy et al (1983) observed that the activities were not affected by dietary GLA. However, Choi and Sugano (1988) found a decrease in $\Delta 6$-desaturase activity in 8-month-old but not in 3week-old rats. On the other hand, Biagi et al (1991) showed an increase in $\Delta 6$-desaturation rate of LA and particularly of LNA. In recent experiments, we observed agedependent variations in $\Delta 6$-desaturation of LA and LNA and in $\triangle 5$-desaturation of DGLA in liver from Wistar rats fed GLA (unpublished results). In obese Zucker rats, dietary GLA bypasses the $\triangle 6$-desaturase and tends to correct the low AA content of tissues (Girault et al, 1992).

Very few experiments have dealt with dietary AA (20:4n-6). In the same set of experiments as above on Zucker rats, we observed very similar effects as with the n-3 long-chain fatty acids EPA + DHA (fig 2), namely a marked decrease in $\triangle 6$-desaturation rate of $L A$, no effect on $\Delta 6$-desaturation rate of $L N A$ and a decrease in $\triangle 5$-desaturation of DGLA but less pronounced than $\Delta 6$-desaturation of LA (unpublished results).
In summary, with regard to the $n-6$ and $n-3$ EFA, the precursors 18:2n-6 and 18:3n3 highly stimulate the desaturases involved in the biosynthesis of longer chain PUFA (20:4n-6, 20:5n-3, 22:6n-3), while these acids present in the diet markedly decrease $\Delta 6$ desaturation of $18: 2 n-6$, less markedly $\Delta 5$ desaturation of $20: 3 n-6$, but do not alter $\Delta 6$ desaturation of 18:3n-3. This explains why biosynthesis of $20: 4 n-6$ was decreased by dietary fish oil. However, dietary 20:4n-6 also decreased 22:6n-3, in phospholipids according to our results. As stated by Zevenberger and Houtsmuller (1989), the $\Delta 6$-desaturase system alone does not totally determine the PUFA levels in tissue lipids. Other factors, such as the incorporation rate of PUFA in tissue phospholipids are also involved.

Other fatty acids are likely to modify desaturation rates. Oleic acid (18:1n-9) can also inhibit $\Delta 6$-desaturase activity but high intake levels are required (Holman, 1964). Data from Periago et al (1989) also indicate that dietary $18: 2 n-6$, compared to $18: 1 n-9$, was much more efficient in stimulating $\Delta 6$ desaturation rate. 
Trans-fatty acids have been reported to inhibit the conversion of LA to AA, especially the $\Delta 6$-desaturation step, as pointed out in previous reviews (Kinsella et al, 1981; Emken, 1984). This effect could be due to essential fatty-acid deficiency. On the contrary, $\Delta 5$-desaturation was either increased (Blomstrand et al, 1985) or not affected (De Gomez Dumm et al, 1983; Mahfouz et al, 1984). Results by Blond et al (1990) showed that dietary heated linseed oil containing 18:3n-3 trans-isomers did not modify liver capacity to desaturate $18: 2 n-6$ and increased $\Delta 5$-desaturation activity. In cultured human skin fibroblasts, trans-fatty acids (elaidate and linoelaidate) are potent inhibitors of $\Delta 6$-desaturation (Rosenthal and Whitehurst, 1983) and $\Delta 5$-desaturation (Rosenthal and Doloresco, 1984).

Cyclopropenoic fatty acids, which possess a cyclopropene ring in the acyl chain, are present in certain oils, such as baobab seed oil. They are potent inhibitors of $\Delta 6$ and $\Delta 5$-desaturation both in vitro and in vivo (Cao et al, 1993). They induced a marked decrease in AA content of tissue phospholipids in rats.

The mechanism by which dietary fatty acids modify the desaturase activity may vary according to the fatty acids. The $\Delta 6$ desaturase is sensitive to feed-back inhibition by the procucts of desaturation and elongation (Brenner, 1981), which is consistent with its high depression by long-chain $n-6$ and $n-3$ polyunsaturated fatty acids. Leikin and Brenner (1989) have reported that a cytosolic factor prevented product inhibition of both $\Delta 6$ - and $\Delta 5$-desaturation by GLA and AA, respectively, as they are formed. Hence, the presence or absence of this factor could regulate the flow of products through this pathway.

These mechanisms intervene in shortterm regulation, or in vitro. However, in vivo, additional mechanisms should be implicated, such as regulation of the amount of desaturase in microsomes. In a recent study.
Osmundsen and Christiansen (personal communication) demonstrated that fish oil diet $(20 \% \mathrm{wt})$ led to $90 \%$ decrease in $\Delta 9$ desaturase activity while the decrease in hepatic $\triangle 9$-desaturase mRNA was $60 \%$. This demonstrated that the $n-3$ polyunsatured fatty acids in fish oil regulate gene expression of $\Delta 9$-desaturase in rat liver. However, since the desaturase activity was less decreased than the desaturase mRNA, other types of regulation must take place such as lower translation rate of mRNA to protein or lower stability of mRNA. Similar results were obtained with soybean oil containing both $18: 2 n-6$ and $18: 3 n-3$ but were less pronounced. If probes for $\Delta 6$ - and $\Delta 5$ desaturases were available, this type of study could be undertaken to assess whether or not $n-6$ and n-3 PUFA are also potent inhibitors of gene expression for $\Delta 6$ and $\Delta 5$-desaturases. The regulation of hepatic gene expression by PUFA has been well documented for enzymes involved in lipogenesis (Clark and Jump, 1993).

Modification by dietary lipids of the phospholipid fatty acid profile of membranes in which the desaturase systems are anchored are also likely to modify the expression of desaturation activity through changes in fluidity.

Nutrients other than fatty acids modulate desaturase activities. Garda and Brenner (1985) reported that, in vitro, the incorporation of cholesterol into rat liver microsomes enhanced the $\Delta 6$ - and $\Delta 5$-desaturase activity, probably by decreasing membrane fluidity. On the contrary, in vivo, cholesterol incorporated into diet decreased the $\Delta 6$ and $\Delta 5$-desaturase activity by a mechanism yet to be elucidated (Leikin and Brenner, 1987; Garg et al, 1988a,b).

Dietary proteins that are important components of diet also modulate desaturase activities. A low dietary intake of proteins evokes, in growing rats, a marked decrease in $\Delta 6$ - and $\Delta 5$-desaturation rate in liver microsomes (Narce et al, 1988). After bal- 
anced refeeding, the desaturase activities are rapidly recovered. High protein intake, ie above $35 \%$ of the calories consumed, increases $\Delta 6$-desaturase activity (Brenner, 1989). Ingested ethanol was also observed to decrease $\Delta 6$ - and $\Delta 5$-desaturase activities (Nervi et al, 1980; Wang and Reitz, 1983).

Data concerning the effect of dietary oligonutrients, such as vitamins and minerals, are very scarce, despite their importance in animal health. Zinc deficiency caused increase in $\Delta 6$-desaturase activity in mammary tissue (Cunnane and Wahle, 1981) while it had no effect on $\Delta 6$ desaturation in liver and decreased the rate of $\Delta 5$ desaturation (Cunnane, 1988). High sodium chloride intake influences $\Delta 6$ - and $\Delta 5$-desaturation rate in rat liver microsomes. When 10-week-old male Wistar rats received $3 \%$ $\mathrm{NaCl}$ in drinking water for $60 \mathrm{~d}$, the $\Delta 6$ desaturation of LA and $\Delta 5$-desaturation of DGLA in liver microsomes were enhanced by 50 and $75 \%$ respectively (Narce et al, 1992). On the contrary, in another set of experiments in 4-week-old genetically normotensive rats (WKY $=$ Wistar-Kyoto) receiving $1 \% \mathrm{NaCl}$ in drinking water for 4 weeks, the $\Delta 6$ - and $\Delta 5$-desaturation rates in liver microsomes were decreased by 25 and $28 \%$ respectively (Poisson et al, 1993b). The observed opposite effects could be due to different experimental conditions: strain and age of rats, amount and duration of salt intake, in particular. The effect evoked by this nutritional situation may involve modifications of steroid secretion (aldosterone) by adrenals.

Another example of relation between a nutritional state and the animal hormonal status is food deprivation. The effects of fasting are probably related to increased glucagon secretion, whereas the effects of refeeding could be related to increased insulin secretion by endocrine pancreas. The effects of fasting have been recently reviewed (Poisson and Cunnane, 1991). Several studies have shown that food depri- vation in rats decreased $\Delta 6$-desaturation of LA. In rats fasting for at least $12 \mathrm{~h}$, compared to control fed rats, the desaturation of LA was only half or less of control (Brenner, 1968; De Gomez Dumm et al, 1970; Brenner et al, 1974). Refeeding fasting animals for only $12 \mathrm{~h}$ with $10 \%$ glucose in the drinking water, largely restored the activity of $\Delta 6$-desaturation, but the increase was transient (De Gomez Dumm et al, 1970). The $\triangle 6$-desaturation of LNA was also decreased in fasting rats while refeeding restored the activity (Brenner, 1974; Nervi et al, 1975). In contrast to $\Delta 6$-desaturation, $\Delta 5$-desaturation rate of DGLA in liver microsomes was increased after $12 \mathrm{~h}$ of fasting in rats previously fed a balanced diet (Lee and Sprecher, 1971). This increase was maintained for $48 \mathrm{~h}$ and then declined to control values after $72 \mathrm{~h}$ of fasting.

\section{Hormonal factors}

Many dietary modifications influence the hormonal status of individuals and the effects of dietary factors on the liver capacity to synthesizing long-chain PUFA from the precursors LA and LNA might be often explained by action of the hormones of which secretion is enhanced or inhibited. Insulin and glucagon are particularly concerned since they are involved in the regulation of energy metabolism in fed and fasting state, respectively. The severe metabolic disturbances observed in the human type 1 diabetes that is insulin-dependent, underlines the importance of this hormone. Moreover, studies on lipid metabolism in diabetes have provided a wealth of information on changes in essential fatty acid metabolism (Poisson and Cunnane, 1991).

Mercuri et al (1966), Brenner et al (1968), Lyman (1971) and Brenner (1989) have shown that the desaturation of LA to GLA was severely depressed in liver microsomes from alloxan-diabetic rats to reach only 
$22-56 \%$ of the control values. Treatment of diabetic animals with insulin corrected this defect in part or totally (table IV). Friedmann et al (1966) also demonstrated in vivo that the synthesis of $A A$ from $L A$ was decreased in alloxan-diabetic rats. Several authors later confirmed that insulin restored to control the $\Delta 6$-desaturation rate of LA and this apparently by enzyme induction, since inhibition of protein synthesis impaired the recovery of enzyme activity (Brenner, 1989). The $\Delta 6-$ desaturation of LNA is also decreased in alloxan-diabetes, but to a lesser extent (Mercuri et al, 1967). The effect is corrected by insulin but after a longer time than for $\Delta 6$ desaturation of LA (Eck et al, 1979). Poisson et al (1978) have demonstrated that $\Delta 5$ desaturation of DGLA into AA was also depressed in alloxan-induced diabetic rats in vivo. This effect was demonstrated to be reversed with subcutaneous injection of insulin to streptozotocin-diabetic rats, providing evidence of insulin regulation of $\Delta 5$ desaturation as a secondary determinant of LA metabolism to AA. The defect in vivo of $\triangle 5$-desaturation of DGLA and its correc-

Table IV. Hormonal factors affecting $\Delta 6$ - and $\Delta 5$-desaturation in rat liver microsomes.

\begin{tabular}{lll}
\hline & $\Delta 6$ & $\Delta 5$ \\
\hline & & \\
Diabetes & - & - \\
Diabetes + insulin & + & + \\
Glucacon & - & - \\
Epinephrine & - & - \\
ACTH & - & - \\
Glucocorticoids & - & - \\
Hypothyroidism & - & - \\
Hypothyroidism + thyroxine & + & + \\
Hyperthyroidism & - & - \\
$\begin{array}{l}\text { Deoxycorticosterone } \\
\text { or aldosterone }\end{array}$ & & \\
$\begin{array}{l}\text { Oestradiol } \\
\text { (in ovariectomized females) }\end{array}$ & - & - \\
\end{tabular}

+ stimulation; - inhibition; references in the text. tion by insulin, have also been shown in rat liver homogenates in vitro (Friedmann et al, 1966).

In the genetically diabetic rat (BB), $\Delta 6$ and $\Delta 5$-desaturation are similarly defective and are restored by insulin injection (Mimouni and Poisson, 1990). As shown in figure 3 , when $B B$ rats were equilibrated by insulin injection $(3 \mathrm{~h}$ ), the $\Delta 6$ - and $\Delta 5$-desaturation rates were similar to values in control Wistar rats. When insulin had decreased in blood (17 and $48 \mathrm{~h}$ ), the desaturation rates had considerably decreased, especially the $\triangle 5$-desaturation of DGLA. Elongation of DGLA was also demonstrated to be insulin dependent (Mimouni et al, 1992). Very recently, Mimouni et al (1994) have examined the $\Delta 4(n-6)$ desaturation in the same strain of rats and shown that the pattern of responses was similar to that of $\Delta 6$ and $\Delta 5-(n-6)$ desaturations with a non-parallel relationship between the desaturation system and the glycemia.

In humans, El Boustani et al (1989) have measured the desaturation of deuterated DGLA into AA in plasma lipids of newly diagnosed diabetics who had never received insulin. After insulin treatment they found that the concentration of deuterated $A A$ increased significantly from pretreatment values, suggesting that insulin was involved in the activity of $\Delta 5$-desaturation in humans. Other studies have similarly suggested that desaturation of LA was sensitive to insulin status (Poisson and Cunnane, 1991).

Glucagon and epinephrine are antagonistic to insulin and depress $\Delta 6$ - and $\Delta 5$ desaturase activity in rat liver microsomal preparations (De Gomez Dumm et al, 1975 , 1976). Glucagon also prevents the refeeding-induced activation of $\Delta 6$-desaturation in previously fasted rats. Depression of $\Delta 6$ desaturation by glucagon and epinephrine is thought to be mediated by stimulation of adenyl cyclase and the subsequent increase in intracellular cyclic AMP, because dibutyryl cyclic AMP induces the same effect as 
glucagon (Brenner, 1977). Glucagon and cAMP also inhibit the phosphorylation of acetyl CoA carboxylase, thereby inhibiting formation of malonyl-CoA. This may decrease the elongation rate of $18: 3 n-6$, the product of $\Delta 6$-desaturation of $18: 3 n-6$. The resulting increased concentration of $18: 3 n$ 6 may reduce the activity of $\Delta 6$-desaturation by feedback inhibition (Brenner and Peluffo, 1969).

Similarly to glucagon and epinephrine, the glucocorticoids also affect the metabolism of glucose and fatty acids. They also inhibit $\Delta 6$-desaturase activity (Brenner, 1981). However, they require more time than epinephrine to inhibit desaturation. The delay was attributed to suppression of protein synthesis. Pituitary adrenal corticotrophic hormone (ACTH) causes a decrease in $\Delta 6$ - and $\Delta 5$-desaturation activity in rat liver and adrenal glands (Mandon et al, 1986). Since ACTH stimulates glucocorticoid secretion, the effect of the hormone may be direct or/and indirect.

$\mathrm{ACTH}$ and glucocorticoids, the secretion of which has a circadian rhythm, may be

$\%$ of control

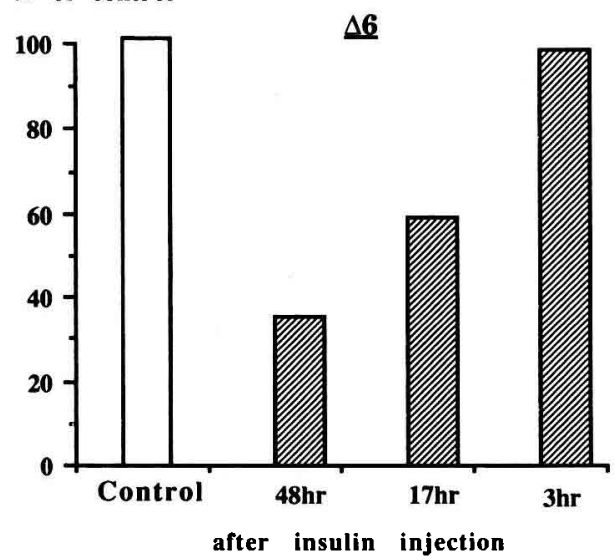

involved in the circadian rhythm of desaturase activities, being lowest around 8 am in normal day-night cycle (Brenner, 1981).

Thyroid hormones are necessary for $\Delta 6$ desaturation since hypothyroidism greatly decreased the $\Delta 6$-desaturation rate of LA in rat liver microsomes (Faas and Carter, 1982). While treatment of hypothyroid rat restores this activity to normal values, hyperthyroidism is associated with a decrease in $\Delta 6$-desaturation (Hoch, 1981; Faas and Carter, 1982). The lower $\Delta 6$-desaturation rate in liver microsomes from obese Zucker rats, compared to their lean littermates, were also ascribed by Blond et al (1989) to hypothyroidism in these animals.

The levels of thyroxine, glucocorticoids, epinephrine and glucagon increase during fasting (Brenner, 1981) and alteration of $\Delta 6$-desaturase activity in fasted rats is probably modulated in part by these metabolic hormones.

Hormones involved in sodium metabolism in kidneys are also active in inhibiting desaturation in rat liver microsomes (De Alaniz and Marra, 1992). These authors observed that when liver micro-

$\%$ of control

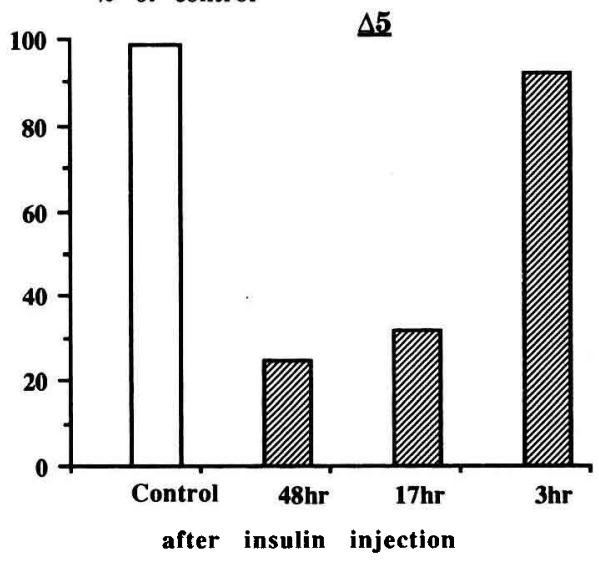

Fig 3. $\Delta 6$ - and $\Delta 5$-desaturation of n-6 essential fatty acids in liver microsomes from female genetically diabetic (BB) rats 3,17 and $48 \mathrm{~h}$ after they have received a subcutaneous injection of insulin compared to control Wistar rats. Values at 17 and $48 \mathrm{~h}$ were not significantly different $(p<0.05)$. They were different from values at $3 \mathrm{~h}$. Those were not significantly different from control values. Reproduced from Mimouni and Poisson (1990). 
somes from deoxycorticosterone- or aldosterone-treated rats were incubated with DGLA, the $\Delta 5$-desaturation rate was considerably reduced, to 38 and $32 \%$ of the control values respectively. High sodium intake decreases aldosterone secretion. This could in part explain the increased $\Delta 6$ desaturation rate observed by Narce et al (1992) in microsomes from rats drinking salted water.

Oestradiol, injected to ovariectomized female rats, decreases the $\Delta 6$-desaturase activity in liver microsomes (Gonzales et al, 1986).

In conclusion, as could be expected, hormones greatly influence desaturation rates in liver and by this means may modify the biosynthesis of long-chain EFA and their availability in tissues. The subsequent modification of fatty-acid profile of membrane phospholipids or the modified availability of substrates for eicosanoid synthesis, could mediate certain properties of hormones and also modify the response of cells to hormone stimulation.

\section{DEVELOPMENT AND AGING}

Regulation of long-chain EFA synthesis in the different stages of life in animals is crucial, since at early ages, the requirement by developing tissues, such as the brain, is elevated, whereas, in aging, different pathologies occur which can be prevented or retarded by suitable dietary intake of EFA (Kinsella, 1991).

The developing brain and central nervous system contain substantial amounts of lipids, both in white matter and myelin (50-70\%) and in grey matter consisting primarily of neuronal cells (nearly $40 \%$ ) (Purvis et al, 1982), that is appreciably more than in most body organs, including liver, kidney and heart. Total phospholipids of brain also have distinctive fatty acyl chain composi- tion, since the ratio of $n-6$ to $n-3$ fatty acids is close to $1: 1$ compared to $4: 1$ in liver, kidney and heart (Bourre et al, 1989). The $20: 4 n-6$ is the prominent member of the $n-6$ family, accounting for $10-15 \%$ of total fatty acyl chains while, in the $n-3$ family $22: 6 n-3$ predominates at $6-15 \%$ of the total. To achieve this tissue-specific composition during normal brain growth and development requires an appropriate supply of PUFA, both in quantity and in balance between the $n-6$ and $n-3$ fatty acids.

Requirements for PUFA are particularly critical for the developing fetus, because of its rapid growth and the early development of its brain. PUFA of the $n-6$ and $n-3$ series, or their precursors LA and LNA, are provided from the mother's blood. When the precursors are provided, they have to be converted into PUFA by the fetus. In rats, liver microsomes were demonstrated to be capable of transforming $18: 2 n-6$ into 18 : $3 n-6$ by $\Delta 6$-desaturation (Satomi and Matsuda, 1973; Pascaud and Strouve-Vallet, 1985; Ravel et al, 1985). They were also capable of transforming 20:3n-6 into 20:4n6 by $\Delta 5$-desaturation (Ravel et al, 1985). The $\Delta 6$-desaturation of $18: 2 n-6$ was also detected in fetus brain microsomes in rats (Pascaud and Strouve-Vallet, 1985) and in mouse brain homogenates (Bourre et al, 1990). Recent in vivo experiments (Green and Yavin, 1993) in which labelled 18:3n-3 and 18:2n-6 were intracranially injected into near-term fetal rats, clearly showed that these acids were converted to long-chain polyenoic derivatives in the fetal brain. Therefore, the fetus can, at least in part, supply its own n-6 and n-3 PUFA requirements. However, especially at the early steps of development, it also relies on its mother's supply.

In animals, the liver is the principal organ capable of synthesizing PUFA from the LA and LNA precursors and to secrete these long-chain fatty acids into the blood. However, in pregnant females, placenta can also 
be a source of PUFA in certain species. While no activity of $\Delta 6$ - and $\Delta 5$-desaturations was detected in rat placenta microsomes (Ravel et al, 1985), the ovine placenta was shown to desaturate 18:2n- 6 into trienoic and tetraenoic fatty acids (Shand and Noble, 1981). The existence of desaturation activity in human placenta is still controversial. Certain authors detected some biosynthesis activity (Zimmermann et al, 1979), while others did not (Chambaz et al, 1985).

Therefore, the developing fetus must depend largely on placental transfer of maternal long-chain EFA, particularly for $n-3$ fatty acids, highly present in neural tissues. This underlines the importance of EFA intake and of the liver desaturation capacity in pregnant women.

After birth, the neonate must also principally rely on mother's milk for supply the long-chain fatty acids for tissue growth (Martin et al, 1993), although $\Delta 6$ - and $\Delta 5$-desaturation activities are present in neonates aged 2-14 d (Poisson et al, 1993a), as they are in human adults (Blond et al, 1981).

Because of its importance, the brain deserves particular alteration. What is the capacity of the developing brain for conversion of extracellar supplies of $18: 3 n-3$ and 18:2n-6 into essential products such as 20:5n-3, 22:6n-3 and 20:4n-6? To what extent does the brain depend on the liver for supplying the essential PUFA? These are important questions regarding the EFA availability in neonates.

In vitro preparation from brain and liver (Cook, 1978) showed that in the very young 10-day-old rats, conversion of 18:2n-6 and $18: 3 n-3$ by $\Delta 6$-desaturation was much higher in brain than in liver. The $\Delta 5$-desaturation of $20: 3 n-6$, although very low in brain, was also significantly higher than in liver. Bourre et al (1983) have demonstrated that mouse brain cells were not capable of synthesizing $22: 6 n-3$ from $18: 3 n-3$ but were capable of taking it up from the medium.
The brain 22:6n-3 would thus have a hepatic origin, being specifically taken up by endothelial cells of brain from the blood lipids (Bourre et al, 1983; Scott and Bazan, 1989). Indeed, as shown by Anderson and Connor (1988), rat brain exhibits a specific capacity in vivo to take up 22:6n-3, although less than liver.

On the other hand, Cook (1991) thinks that the brain is capable of synthesizing 22:6n-3. Indeed Spector and Moore (1992) by using cultured endothelial cells from brain vessels, cultured astrocytes, and cultured neurons from rats, clearly showed that endothelial cells and astrocytes actively cooperated in synthesizing 22:6n-3 and providing it to neurons. Endothelial cells extensively convert $18: 3 n-3$ to $20: 5 n-3$ while astrocytes convert the latter into $22: 6 n-3$ available for neurons. Synthesis of 20:4n-6 from 18:2n-6 would follow the same pathway.

As animals are growing older, the capacity of liver to desaturate n-6 and n-3 fatty acids increases while that of brain decreases (Cook, 1991). However, at high ages desaturation in vitro of fatty acids in rat liver (Peluffo and Brenner, 1974; Bordini et al, 1988; Choi et al, 1989; Biagi et al, 1991) and in mouse liver (Bourre et al, 1990) was shown to decrease. In a recent study (Maniongui et al, 1993), we have measured $\Delta 6$ desaturation of $18: 2 n-6$ and $18: 3 n-3$ and $\Delta 5$-desaturation of 20:3n-6 in liver microsomes from rats fed a balanced diet throughout their life from 1.5 to 24 months of age. The results were expressed as specific activity and as liver capacity to desaturate by taking into account the liver weight which increased from $6.8 \mathrm{~g}$ at 1.5 month to $14.1 \mathrm{~g}$ at 24 months. The results illustrated in figure 4 show that specific activity of 18:2n-6 had not decreased from 1.5 to 24 months of age, despite some variation throughout the life. Since the liver weight increased, the liver capacity to desaturate 18:2n-6 increased up to 6 months to reach a plateau from 6 to 24 months. The time- 
course of $\Delta 6$-desaturation of $18: 3 n-3$ was different from that of $18: 2 n-6$, since it increased from 1.5 to 3 months and then regularly decreased. However, the liver capacity to desaturate $18: 3 n-3$ was not different at 1.5 and 24 months. The $\Delta 5$-desaturation of 20:3n-6 varied with age very differently from $\Delta 6$-desaturation of $18: 2 n-6$. It was nearly 6 -fold higher at 1.5 months and fell to nearly the same value at 3 months. From then on, $\Delta 5$-desaturation slowly increased up to 24 months. At this age, the liver capacity to desaturate $20: 3 n-6$ was not significantly different from that measured at 1.5 months.

These data demonstrated that the liver capacity to synthesize $20: 4 n-6$ from $18: 2 n-6$ did not decrease with age in rats. This was reflected in 20:4n-6 content of liver microsomal phospholipids (fig 5) and of erythrocyte lipids, which increased from 1.5 to 20 months. In these experiments, the liver capacity to convert $20: 4 n-3$ to $20: 5 n-3$ by $\Delta 5$-desaturation was not determined, because commercial labelled precursor was not available. The liver capacity to desaturate $18: 3 n-3$ was not decreased at 24 months, and the liver microsome phospholipid content in 22:6n-3 was not significantly different at 1.5 and 24 months (12.9 and $12.5 \mathrm{~mol} \%$ respectively).

These results clearly show that in rats fed a balanced diet, if desaturation capacity of liver is evaluated in the whole organ, no decrease occurs from 1.5 to 24 months. This is reflected in the unchanged or even increased content in polyunsaturated $n-6$ and $n-3$ fatty acids of the membrane lipids studied.

In humans, the liver desaturation activities are much lower than in rats (De Gomez Dumm and Brenner, 1975; Blond et al, 1981). Despite that, several studies have shown that few differences exist between elderly and young subjects with respect to the $n-6$ and $n-3$ fatty acid content of serum (Holman et al, 1979; Asciutti-Moura et al,
1988), erythrocyte (Driss et al, 1988) and platelet (Vericel et al, 1988) phospholipids.

It can thus be assumed that in humans, as in rats, the desaturation activities are regulated to maintain constant PUFA levels in membrane phospholipids.
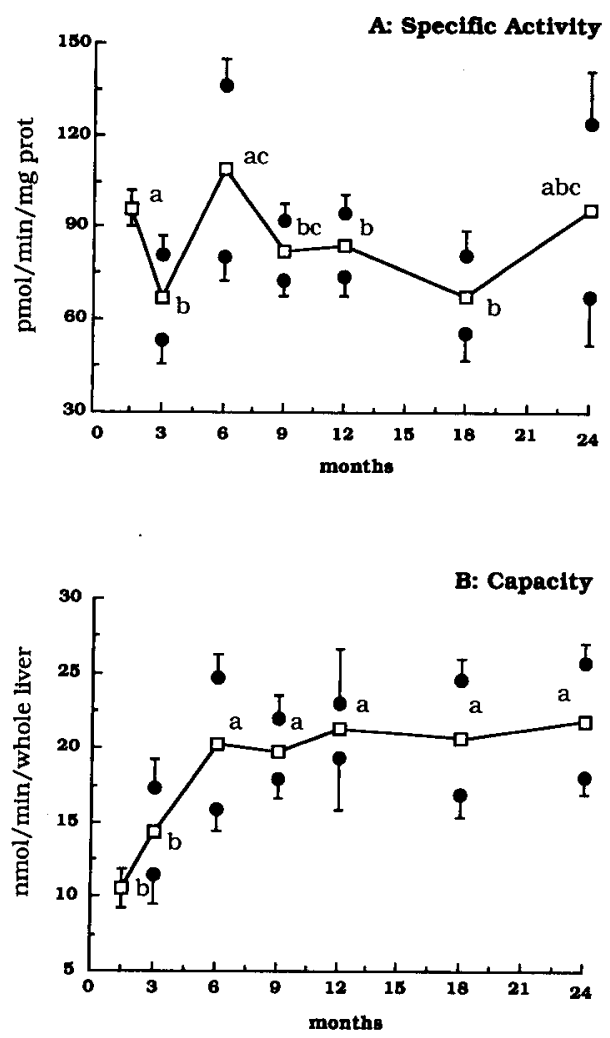

Fig 4. Age-related changes in $\Delta 6$-desaturation of linoleic acid (18:2n-6) in liver microsomes expressed both as specific activity of liver microsomes (A) and activity of whole liver or capacity (B). Results are means \pm SD obtained from 1 group of 6 rats ( 1.5 months) or 2 groups of 3 rats at all other ages. After analysis of variance using the Fisher multiple range test, means of the 6 rats for each age were compared according to the least significant difference and classified in decreasing order. Means assigned different superscript letters were significantly different $(P<0.05)$. Prot: protein. Reproduced from Maniongui et al (1993). 


\section{OXIDATION OF ESSENTIAL FATTY ACIDS}

When entering the animal cells, EFA compete for several metabolic pathways in different compartments of the cell, generally anabolic pathways (microsomal esterification) and catabolic pathways (mitochondrial and peroxisomal $\beta$-oxidation). Generally, especially in the liver, regulation of oxidation may modulate availability of fatty acids for esterification. However, the regulation of the activity of other enzymes such as acyltransferases can also direct acids to synthesis of phospholipids, cholesteryl esters or even triacylglycerols.

The overall oxidation of fatty acids in the body results in $\mathrm{CO}_{2}$ production depending on fatty-acid structure. Leyton et al (1987) have investigated the difference in rates of whole-body oxidation of essential PUFA in the rat. Using radiolabelled substrates, the oxidation rate of oleic (18:1n-9), linolenic

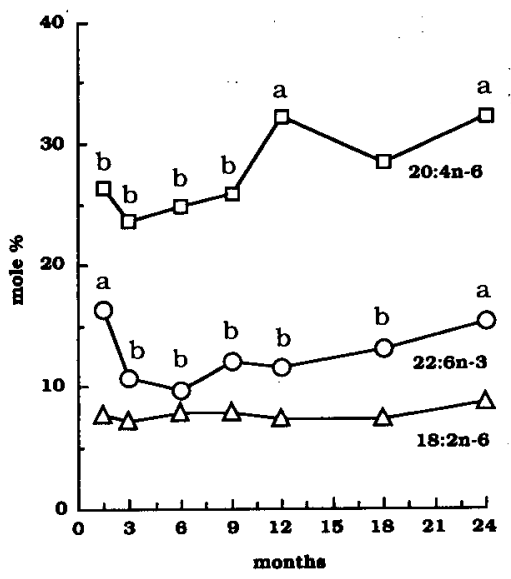

Fig 5. Age-related changes in percentages of major polyunsaturated fatty acids in liver microsomal phospholipids. Results are means from 6 rats at each age. After analysis of variance using the Flsher multiple range test, the means were compared according to the least significant difference and classified in decreasing order. Means assigned different superscript letters were significantly different $(p<0.05)$. Reproduced from Maniongui et al (1993). (18:2n-6), $\alpha$-linolenic (18:3n-3), $\gamma$-linolenic (18:3n-6), dihomo- $\gamma$-linolenic acid (20:3n-6) and arachidonic (20:4n-6) acids was determined by measuring the extent of label expired in $\mathrm{CO}_{2}$ over a $24 \mathrm{~h}$ period. Labelled fatty acids were administrated orally dissolved in olive oil. The results, illustrated in figure 6, are expressed as percentage of radioactivity administrated. Seven hours after oral administration of fatty acid, nearly $50 \%$ of the radioactivity supported by 18 : $1 \mathrm{n}-9$ was recovered as ${ }^{14} \mathrm{CO}_{2}$. For the other unsaturated fatty acids, the amount of recovered radioactivity decreased in the order: $18: 1 n-9(49 \%)>18: 3 n-3(41 \%)>18: 2 n-6$ $(27 \%)>18: 3 n-6(13 \%)>20: 3 n-6=20: 4 n-6$ $(4 \%)$. The order was the same after $24 \mathrm{~h}$ except that $18: 3 n-3$ was recovered to a greater extent than 18:2n-6.

From these data, it is evident that longchain essential n- 6 fatty acids were oxidized to $\mathrm{CO}_{2}$ at a very low rate, much lower than the 'parents' $18: 2 n-6$ and $18: 3 n-3$. This is evidence that when provided as very longchain fatty acids, the EFA are required in lower amount in the diet than the precursors $18: 2 n-6$ and $18: 3 n-3$.

The same type of experiment has been carried out in humans using [ $\left.{ }^{13} \mathrm{C}\right]$-labelled fatty acids (Jones et al, 1985). [ $\left.{ }^{13} \mathrm{C}\right]$ Oleic, $\left[{ }^{13} \mathrm{C}\right]$ linoleic or $\left[{ }^{13} \mathrm{C}\right]$ stearic acid was given in a capsule together with the breakfast meal to male adult volunteers. Subjects were confined to a metabolic ward and provided 6 min breath samples hourly during a $10 \mathrm{~h}$ period, for ${ }^{13} \mathrm{CO}_{2}$ enrichment analysis by mass spectroscopy. Results showed that the oxidation rate was in the order: $18: 1 n-9$ $>18: 2 n-6>18: 0$.

The maximum of ${ }^{13} \mathrm{CO}_{2}$ excretion was observed $6 \mathrm{~h}$ after oral administration for the first 2 fatty acids. It was delayed for 18:0. During the 6th hour, ${ }^{13} \mathrm{C}$ recovered by oxidation of $18: 1 n-9$ was around $2.8 \%$ of the absorbed dose. It was $2.0 \%$ for $18: 2 n-6$ and $0.1 \%$ for $18: 0$, that is 28 -fold less than for 18:1n-9. 
As in rats (Leyton et al, 1987), 18:2n-6 in humans is oxidized at lower rate than $18: 1 n-9$. Oxidation by tissues thus limits the availability of the absorbed LA. The same is probably true, in humans, for LNA as well.

In the whole body, the oxidation rate of fatty acids by tissues depends on the rate of their uptake by the cells and the rate of their oxidation inside the cells. The uptake rate of fatty-acids from the blood depends itself on tissue or organ specificity, on fatty-acid specificity and on whether or not the fatty acid is esterified. Although the EFA are principally present in the blood in an esterified form, especially following their intestinal absorption (Carlier et al, 1991), most of the experiments undertaken for studying differential uptake by tissues have utilized free fatty acids. In that case, the data reported above and those obtained by Anderson and Connor (1988) have clearly shown that, per unit of wet tissue, the liver took up fatty acids in greater amounts than the brain, 13-38 times more depending on the fatty acid, although the rats were very young and the need for fatty acids of the developing brain was very high. Apparently, other organs and tissues in the rat take up fatty acids less rapidly than liver (Ong et al, 1977). However, because of their weight in animals, skeletal muscles and adipose tissue play a major role in uptake (adipose tissue) and oxidation (muscles) of fatty acids. But liver occupies a key position because, like intestine, it possesses the ability to provide tissues with secreted fatty acids. Whether or

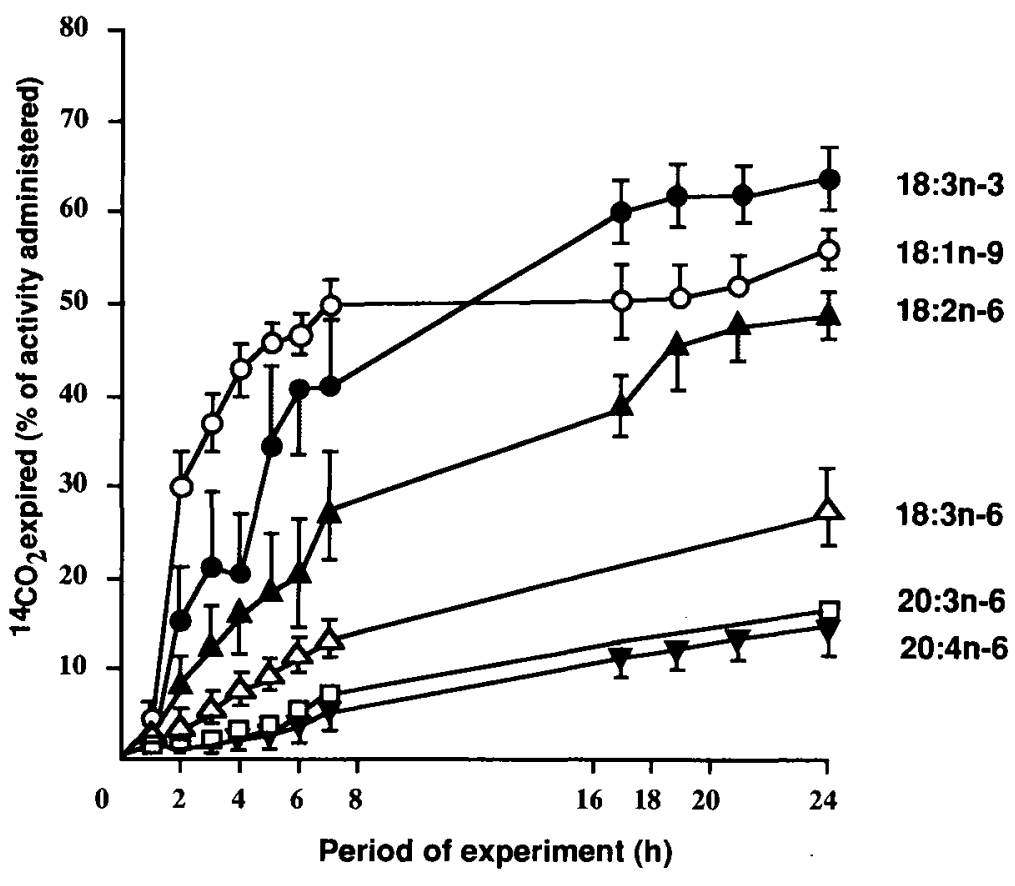

Fig 6. The in vivo oxidation of unsaturated fatty acids in rats a 24-h period. Each animal received an oral dose of $5-6 \mu \mathrm{Ci}{ }^{14} \mathrm{C}$-labelled fatty acid in $0.2 \mathrm{ml}$ olive oil and was put into a metabolism chamber and the expired ${ }^{14} \mathrm{CO}_{2}$ was collected. Points are mean values, with their standard errors represented by vertical bars, for the radioactivity recovered in $\mathrm{CO}_{2}$ from $\left(1-{ }^{-14} \mathrm{C}\right) \alpha$-linolenic acid $(-) ;\left(1-{ }^{-14} \mathrm{C}\right)$ oleic acid $(\mathrm{O}),\left(1-{ }^{14} \mathrm{C}\right)$ linoleic acid $(\mathbf{\Delta}),\left(1-{ }^{14} \mathrm{C}\right) \gamma$-linolenic acid $(\Delta),\left(1-{ }^{14} \mathrm{C}\right)$ dihomo- $\gamma$-linolenic acid $(\square)$ and $\left(1-{ }^{14} \mathrm{C}\right)$ arachidonic acid $(\boldsymbol{\nabla})$. Reproduced from Leyton et al (1987). 
not fatty acids are taken up by the liver, more or less rapidly according to acyl-chain specificity is still controversial. Christensen et al (1986) observed that, at a given free fatty acid/serum albumin molar ratio, the uptake of unsaturated fatty acids was identical whatever the fatty acids. This confirmed results by Kohout et al (1971) in perfused liver for saturated and unsaturated fatty acids. On the contrary, Anderson and Connor (1988) have shown that, in vivo, liver of very young rats took up 22:6n-3 4 times more rapidly than 18:3n-3.

The mechanism of fatty-acid uptake by animal cells has not been fully elucidated. In spite of strong evidence for carrier-mediated uptake and possibly for active transport, it is still argued that fatty-acid uptake occurs by spontaneous and non-specific diffusion of fatty acids across the plasma membrane (Schulz, 1991).

Inside the cell, fatty acids are channelled to different metabolic pathways, possibly by fatty-acid binding proteins (FABP) (Schulz, 1991). In most cells, particularly in hepatocytes, the 2 major routes are esterification in endoplasmic reticulum and oxidation in mitochondria and peroxisomes. In liver, regulation of oxidation of fatty acids generally determines their availability for esterification. However, the esterification pathway is also regulated. Fish oil diets that greatly increase mitochondrial and peroxisomal $\beta$ oxidation of fatty acids, conversely decrease phosphatidate hydrolysis and thence glycerolipid synthesis (Halminski et al, 1991). The tissues and organs in animals display different oxidative capacities. In experiments with homogenates of liver, heart muscle and quadriceps muscle, Reubsaet et al (1989) have observed that the fatty-acid oxidation rate in the heart was 52 to $93 \%$ that of the liver, whereas the rate in the skeletal muscle was only 9 to $35 \%$ of the liver capacity.

The contribution of mitochondria and peroxisomes to fatty-acid oxidation highly depends on the fatty acid (Osmundsen et al, 1991). In their study on tissue homogenates, Reubsaet et al (1989) have observed that the contribution of peroxisomal fatty acid oxidation to overall tissue oxidation was, depending on the fatty acid, 15 to $28 \%$ in liver, 14 to $46 \%$ in heart and 18 to $38 \%$ in the quadriceps muscle. The difference is assumed to be the mitochondrial oxidation. In liver homogenate, 20:4n-6, $22: 4 n-6$ and $18: 1 n-9$ were preferentially (> $80 \%$ ) oxidized by mitochondria. 18:2n-6 was also principally oxidized by mitochondria but to a lesser extent (72\%). Some differences between tissues were demonstrated in this study. In a similar experiment in isolated liver cells, Christensen et al (1986) observed that $22: 4 n-6$ and $20: 5 n-3$ were oxidized to a greater extent in peroxisomes than $18: 1 n-9,18: 2 n-6,20: 4 n-6$ and $22: 6 n-3$. In this experiment, $75 \%$ of $22: 4 n-6$ oxidation was in peroxisomes. The difference between the 2 experiments with regard to the location of $22: 4 n-6$ oxidation may be due to the model used.

Osmundsen et al (1987) have measured fatty-acid oxidation on isolated mitochondria and peroxisomes. They observed that in mitochondria, 18:tn-9, 18:2n-6, and 18:3n-3 were oxidized at nearly equal rates, while $18: 3 n-6,20: 4 n-6$ and $22: 6 n-3$ were poorly oxidized. In peroxisomes, 18:3n-3, 18:3n-6 and $22: 6 n-3$ were particularly well oxidized.

Clouet et al (1989) have observed that the oxidation rate of 18:3n-3 was higher than that of $18: 2 n-6$ and $18: 1 n-9$ in isolated rat liver mitochondria. The reason was the specific activity of the enzyme carnitine palmitoytransferase I (CPTI) measured in the mitochondrial outer membranes. Figure 7 shows that the CPTI activity towards $18: 3 n-3$ was higher than towards $18: 2 n-6$ and $18: 1 n-9$ and that the activity increased with the ratio of fatty acid/albumin and more rapidly for 18:3n-3. Gavino and Gavino (1991) have confirmed these results by measuring the CPT initial velocity and additionally showed that the initial velocity was very low for $20: 4 n-$ 


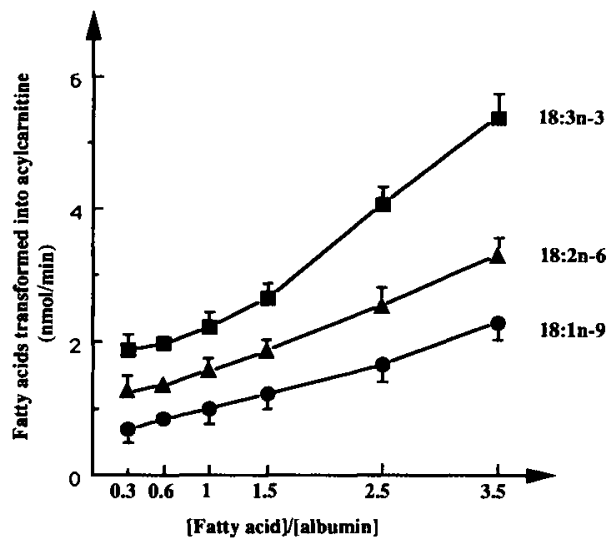

Fig 7. Carnitine palmitoyltransferase I activity measured with octadecenoic acids in outer mitochondrial membranes of rat liver at different fatty acid/albumin ratios. $\alpha$-Linolenic acid (n-3); $\boldsymbol{\Delta}$ linoleic acid (n-6), oleic acid (n-9). Reproduced from Clouet et al (1989).

6 and $22: 6 n-3$ but relatively high for $20: 5 n-3$, studied as acyl-CoA. They suggested that acyl-CoA synthesis may also be important in the control of the entry of fatty acids into the mitochondria, in addition to specificity of CPTI to fatty acyl-CoA. In this view, Singh et al (1987) have postulated that acyl-CoA synthesis for very long-chain fatty acids was absent or was of low activity in mitochondria and for this reason, these fatty acids were directed to peroxisomal oxidation.

Factors that increase fatty-acid oxidation, in particular in peroxisomes, are likely to decrease the availability of essential fatty acids in the cell. Malonyl-CoA is a potent inhibitor of carnitine palmitoyltransferase in mitochondria and any factor which decreases malonyl-CoA synthesis such as glucagon, increases mitochondrial fatty-acid oxidation. The reverse is true for insulin, which strongly stimulates malonyl-CoA synthesis and lipogenesis and decreases fattyacid oxidation. The stimulation of peroximal oxidation activity seems to be mediated by accumulation of fatty acyl-CoAs in the cell (Osmundsen et al, 1991). The activity is very sensitive to nutritional factors.

In livers of rats fed high-fat diets, peroxisomal $\beta$-oxidation is stimulated, in particular when the diet contains a high proportion of very long-chain fatty acids, as in hydrogenated fish oils, known to be poorly $\beta$-oxidized in mitochondria (Osmundsen et al, 1991). Polyunsaturated $n-3$ fatty acids are particularly potent stimulators of oxidation. Repeated administration of EPA (20:5n-3) ethyl ester to rats enhances the activity of enzymes involved in mitochondrial and peroxisomal fatty-acid oxidation (Aarsland et al, 1990). Willumsen et al (1993) have recently confirmed that prolonged administration of EPA to rats increased peroxisomal and mitochondrial fatty-acid oxidation in isolated hepatocytes. Fish oil was also observed to stimulate peroxisomal capacity to oxidize fatty acids, but not safflower oil containing nearly $85 \%$ 18:2n-6 (Halminski et al, 1991). Vamecq et al (1993) confirmed these results and considerably extended studies on regulation of fatty acid mitochondrial and peroxisomal oxidation by n-3 PUFAs. When rats were given diets enriched in $n-3$ and $n-6$ fatty acids, varying in $n-3 / n-6$ fatty acid ratio, peroxisomal $\beta$ oxidation of lauroyl-CoA in liver increased with increasing ratio, being nearly 3 -fold higher when the ratio increased from 0.12 to 10. In these circumstances, mitochondrial $\beta$-oxidation of butyryl-CoA was not increased in liver, whereas the activity of mitochondrial acyltransferases was enhanced with the higher $n-3 / n-6$ fatty-acid ratio. In heart, the peroxisomal and mitochondrial fatty-acid oxidation was also increased but to a lesser extent and only at high ratios. Ultrastructural studies additionally showed that in hepatocytes of rats fed the high fat diet with the highest n-3/n-6 fatty-acid ratio, the number and the fractional volumes of peroxisomes and mitochondria were higher than with the lowest ratio. 
These data definitely establish that dietary n-3 PUFA induce the enhancement of peroxisomal fatty acid oxidation and also mitochondrial oxidation, but less strongly. The beneficial effect of $n-3$ PUFA is to lower hypertriglyceridaemia, by decreasing liver VLDL secretion, in animals and humans. A possible adverse effect is to decrease the availability of $n-6$ polyunsaturated fatty acids (20:4n-6) reinforcing in this way the inhibiting effect of polyunsatured n-3 fatty acids on $\Delta 6$-and $\Delta 5$-desaturation capacity of n-6 fatty acids in liver microsomes (fig 2).

In conclusion, n-6 and n-3 essential fatty acids should be provided with the diet in balanced proportion. An n-6/n-3 fatty acid ratio comprised between 4 and 6 is generally recommended as the most beneficial. They must also be provided in sufficient amounts to optimise their biological functions but not in too high amounts to avoid possible adverse effects. In healthy subjects, a dietary intake of both parent EFA (18:2n-6, $18: 3 n-3)$ of $4-6$ or $7 \%$ of total energy intake could be recommended. But it depends on the other dietary components: very longchain n- 6 and $n-3$ fatty acids, the other dietary fatty acids, saturated, monounsaturated, trans-fatty acids, protein and starch etc. It also depends on the physiological state: pregnancy, nursing, growth or aging. Pathological states are likely to greatly modify the EFA requirements because of defects in the very-long-chain PUFA biosynthesis. However, in healthy individuals, despite the numerous factors likely to influence the availability of EFA, a regular and balanced diet usually meets the tissue requirements in $n-6$ and $n-3$ EFA.

\section{ACKNOWLEDGMENTS}

We are grateful to $\mathrm{H}$ Carlier and JP Poisson for their advice in the preparation of this review, and JM Cao for his precious help in editing the manuscript and its illustrations.

\section{REFERENCES}

Aarsland A, Lundquist M, Borretsen B, Berge RK (1990) On the effect of peroxisomal $\beta$-oxidation and carnitine palmitoyltransferase activity by eicosapentaenoic acid in liver and heart from rats. Lipids 25, 546-548

Anderson GJ, Connor WE (1988) Uptake of fatty acids by the developing rat brain. Lipids 23, 286-290

Asciutti-Moura LS, Guilland JC, Fuchs F, Richard D, Klepping $J(1988$ ) Fatty-acid composition of serum lipids and its relation to diet in an elderly institutionalized population. Am J Clin Nutr 48, 980-987

Bernard A, Carlier H (1989) Absorption and metabolism of lipids. In: Intestinal Metabolism of Xenobiotics (AS Koster, E Richter, F Lauterbach, F Hastmann, eds) Progr Pharmacol Clin Pharmacol, Gustav Fisher, Stuttgart, Germany, 217-230

Bernard A, Caselli C, Carlier H (1991) Linoleic acid chyloportal partition and metabolism during its intestinal absorption. Ann Nutr Metab 35, 98-110

Bernert J, Sprecher H (1975) Studies to determine the role rates of chain elongation and desaturation play in regulating the unsaturated fatty-acid composition of rat liver lipids. Biochim Biophys Acta 398, 336340

Bézard J, Bugaut M (1986) Absorption of glycerides containing short, medium and long chain fatty acids. In: Fat Absorption (A Kuksis ed) CRC Press Inc, Boca Raton, FL, USA, 119-158

Biagi PL, Bordoni A, Hrelia S, Celadon M, Horrobin DF (1991) $\gamma$-Linolenic acid dietary supplementation can reverse the aging influence on rat liver microsome $\Delta 6$-desaturase activity. Biochim Biophys Acta 1083, 187-192

Bjerve KS, Mosted IL, Thoresen L (1987) $\alpha$-Linolenic acid deficiency in patients on long-term gastric tube feeding: estimation of linolenic acid and long chain unsaturated $n-3$ fatty acid requirements in man. $A m$ $J$ Clin Nutr 45, 66-77

Bjerve KS, Fischer S, Wammer F, Egeland T (1989) $\alpha$ linolenic acid and long-chain $\omega-3$ fatty acid supplementation in three patients with $\omega-3$ fatty acid deficiency: effect on lymphocyte function, plasma and red cell lipids, and prostanoid formation. Am J Clin Nutr $49,290-300$

Blomstrand RF, Diczfaluzy V, Sisfontes L, Svensson L (1985) Influence of dietary partially hydrogenated vegetable and marine oils on membrane composition and function of liver microsomes and platelets in the rat. Lipids 20, 283-295

Blond JP, Lemarchal P (1984) A study of the effect of $\alpha$ linolenic acid on the desaturation of dihomo-gammalinolenic acid using rat liver homogenates. Reprod Nutr Dev 24, 1-10

Blond JP, Bézard J (1991) $\Delta 5$-desaturation of dihomogamma-linolenic acid $(20: 3(n-6))$ into arachidonic 
acid (20:4(n-6)) by rat liver microsomes and incorporation of fatty acids in microsome phospholipids. Biochim Biophys Acta 1084, 255-260

Blond JP, Lemarchal P, Spielman D (1981) Désaturation comparée des acides linoléique et dihomo-gammalinolénique par des homogénats de foie humain in vitro. CR Acad Sci Paris 292, 911-914

Blond JP, Henchiri C, Bézard J (1989) $\Delta 6$ and $\Delta 5$ desaturase activities in liver from obese Zucker rats at different ages. Lipids 24, 389-395

Blond JP, Henchiri C, Precigou P, Grandgirard A, Sebedio J (1990) Effect of 18:3n-3 geometrical isomers of heated linseed oil on the biosynthesis of arachidonic acid in rats. Nutr Res 10, 69-79

Bordini A, Biagi PL, Turchetto E Hrelias (1988) Aging influence on delta- 6 desaturase activity and fatty acid composition of rat liver microsomes. Biochem Intern 17, 1001-1009

Bottino NR, Vandenberg GA, Reiser R (1967) Resistance of certain long-chain polyunsaturated fatty acids of marine oils to pancreatic lipase hydrolysis. Lipids 2, 489-493

Bourre JM, Faivre A, Dumont $O$ et al (1983) Effect of polyunsaturated fatty acids on fetal mouse brain cells in culture in a chemically defined medium. J Neurochem 41, 1234-1242

Bourre JM, François M, Youyou A et al (1989) The effects of dietary $\alpha$-linolenic acid on the composition of nerve membranes, enzymatic activity, electrophysiological parameters, resistance to poisons and performance of learning tasks in rats. $J$ Nutr $119,1880-1892$

Bourre JM, Piciotti M, Dumont O (1990) $\Delta 6$ desaturase in brain and liver during development and aging. Lipids 25, 354-356

Brenner RR (1971) The desaturation steps in the animal biosynthesis of polyunsaturated fatty acids. Lipids $6,567-575$

Brenner RR (1974) The oxidative desaturation of unsaturated fatty acids in animals. Mol Cell Biochem 3 , 41-52

Brenner RR (1977) Regulatory function of delta- 6 desaturase-key enzyme on polyunsaturated fatty acid synthesis. In: Function and Biosynthesis of Lipids (NG Bazan, RR Brenner, NM Ginsto, eds), Plenum Press, New York, USA, 85-101

Brenner RR (1981) Nutritional and hormonal factors influencing desaturation of essential fatty acids in animals. Prog Lipid Res 20, 41-47

Brenner RR (1989) Factors affecting chain elongation and desaturation. In: The Role of Fats in Human Nutrition (AJ Vergroesen, MA Crawford, eds), Academic Press, San Diego, CA, USA, 45-80

Brenner RR, Peluffo RO (1969) Regulation of unsaturated fatty-acid biosynthesis. I. Effect of unsaturated fatty acids of 18 carbons on the microsomal desaturation of linoleic acid into $\gamma$-linolenic acid. Biochim Biophys Acta 176, 471-479
Brenner RR, Peluffo RO, Mercuri O, Restelli MA (1968) Effect of arachidonic acid in the alloxan-diabetic rat. Am J Physiol 215, 63-70

Brenner $\mathrm{R}$, Garda $\mathrm{H}$, de Gomez Dumm INT, Pezzano $H$ (1981) Early effects of EFA deficiency on the structure and enzymatic activity of rat liver microsomes. Prog Lipid Res 20, 315-321

Brockerhoff H, Yurkowski M (1966) Stereospecific analysis of several vegetable fats. J Lipid Res 3, 24-29

Brockerhoff H, Hoyle RG, Wolmark N (1966) Positional distribution of fatty acids in triglycerides of animal depot fats. Biochim Biophys Acta 116, 67-72

Brockerhoff $\mathrm{H}$, Hoyle J, Hwang PC, Litchfield C (1968) Positional distribution of fatty acids in depot triglycerides of aquatic animals. Lipids 3, 24-29

Burr GO, Burr MM (1929) A new deficiency disease produced by the rigid exclusion of fat from the diet. $J$ Biol Chem 82, 345-367

Cao JM, Blond JP, Bézard J (1993) Inhibition of fatty acid $\Delta 6$ - and $\Delta 5$-desaturation by cyclopropene fatty acids in rat liver microsomes. Biochim Biophys Acta 1210, 27-34

Carlier H, Bernard A, Caselli C (1991) Digestion and absorption of polyunsaturated fatty acids. Reprod Nutr Dev 31, 475-500

Carlson S, Cooke R, Rhodes P, Peeples J, Werkman $S$ (1992) Effects of vegetable and marine oils in preterm infant formulas on blood arachidonic and docosahexaenoic acids. J Pediatr 120, 159-167

Caselli C, Bernard A, Blond JP, Besnard P, Carlier H (1993) Intestinal conversion of linoleic acid to arachidonic acid in the rat. $J$ Nutr Biochem 4, 655-658

Castuma JE, Catala A, Brenner RR (1972) Oxidative desaturation of eicosa-8, 11-dienoic acid to eicosa$5,8,11$-trienoic acid. Comparison of different diets on oxidative desaturation at the 5,6 and 6,7 positions. J Lipid Res 13, 783-789

Chambaz J, Ravel D, Manier MC, Pepin D, Mulliez N, Bereziat $G$ (1985) Essential fatty acids interconversion in the human fetal liver. Biol Neonate 47, 136140

Chen IS, Subramaniam S, Cassidy MM, Sheppard AJ Vahouny GV (1985) Intestinal absorption and lipoprotein transport of $(\omega 3)$ eicosapentaenoic acid. $J$ Nutr $115,219-225$

Chen IS, Le T, Subramaniam S, Cassidy MM, Sheppard AJ, Vahouny GV (1987) Comparison of the clearances of serum chylomicron triglycerides enriched with eicosapentaenoic acid or oleic acid. Lipids 22, 318-321

Choi YS, Sugano M (1988) Effects of dietary $\alpha$ - and $\gamma-$ linolenic acids on lipid metabolism in young and adult rats. Ann Nutr Metabol 82, 169-176

Choi YS, Goto S, Ikeda I, Sugano M (1989) Effect of dietary n-3 polyunsaturated fatty acids on cholesterol synthesis and degradation in rat of different ages. Lipids $24,45-50$ 
Christensen E, Hagve TA, Christophersen BO (1986) Mitochondrial and peroxisomal oxidation of arachidonic and eicosapentaenoic acid studied in isolated liver cells. Biochim Biophys Acta 879, 313-321

Christiansen K, Gan MY, Holman RT (1969) Sex differences in the metabolism of fatty acids in vitro. Biochim Biophys Acta 187, 19-25

Christiansen EN, Lund JS, Rortveit T, Rustan CR (1991) Effect of dietary n-3 and n-6 fatty acids on fatty-acid desaturation in rat liver. Biochim Biophys Acta 1082, 57-62

Christie WW, Moore JH (1970a) A comparison of the structures of triglycerides from various pig tissues. Biochim Biophys Acta 210, 46-56

Christie WW, Moore JH (1970b) The structure of egg yolk triglycerides. Biochim Biophys Acta 218, 83-88

Clark SD, Jump DB (1993) Regulation of gene expression by dietary fats: a unique role for polyunsaturated fatty acids. In: Nutrition and Gene Expression (CD Berdanier, JL Hargrove, eds), CRC Press, Boca Raton, CA, USA, 227,246

Clouet P, Niot I, Bézard J (1989) Pathway of $\alpha$-linolenic acid through the mitochondrial outer membrane in the rat liver and influence on the rate of oxidation. Biochem J 263, 867-873

Cook HW (1978) In vitro formation of polyunsaturated fatty acids by desaturation in rat brain: some properties of the enzyme in developing brain and comparison with liver. $J$ Neurochem $30,1327-1334$

Cook HW (1991) Brain metabolism of $\alpha$-linolenic acid during development. Nutrition 7, 440-442

Cook H, Byers D, Palmer F et al (1991) Alternate pathways in the desaturation and chain elongation of linolenic acid, 18:3(n-3), in cultured glioma cells. J Lipid Res 32, 1265-1273

Cunnane SC (1988) Role of zinc in lipid and long-chain fatty-acid metabolism and in membranes. Prog Food Nutr Sci 12, 131-188

Cunnane SC, Wahle KWJ (1981) Zinc deficiency increases the rate of $\Delta 6$ desaturation of linoleic acid in rat mammary tissue. Lipids $16,771-774$

Curtis-Prior (1988) Prostaglandins: Biology and Chemistry of Prostanglandins and Related Eicosanoids. Churchill Livingstone, New York, USA

De Alaniz MJT, Marra CA (1992) Glucocorticoid and mineralocorticoid hormones depress liver $\Delta 5$-desaturase activity through different mechanisms. Lipids 27, 599-604

De Gomez Dumm INT, Brenner RR (1975) Oxidative desaturation of $\alpha$-linolenic, linoleic and stearic acids by human liver microsomes. Lipids 10, 315-317

De Gomez Dumm INT, De Alaniz MJT Brenner RR (1970) Effect of diet on linoleic acid desaturation and some enzymes of carbohydrate metabolism. $J$ Lipid Res 11, 96-101

De Gomez Dumm INT, De Alaniz MJT, Brenner RR (1975) Effects of glucagon and dibutyryl adenosine
3', 5'-cyclic monophosphate on oxidative desaturation of fatty acids in the rat. J Lipid Res $16,264-268$

De Gomez Dumm INT, De Alaniz MJT, Brenner RR (1976) Comparative effect of glucagon, dibutyryl cyclic AMP, and epinephrine on the desaturation and elongation of linoleic acid by rat liver microsomes. Lipids 11, 833-836

De Gomez Dumm INT, De Alaniz MJT, Brenner RR (1983) Effect of dietary fatty acids on $\Delta 5$ desaturase activity and biosynthesis of arachidonic acid in rat liver microsomes. Lipids 18, 781-788

Demandre C, Trémolieres A, Justie AM, Mazliak P (1986) Oleate desaturation in six phosphatidylcholine molecular species from potato tuber microsomes. Biochim Biophys Acta 877, 380-386

Deuel HJ Jr (1955) Digestibility studies on fats, oils and fatty acids. In: The Lipids: Their Chemistry and Biochemistry (H Deuel, ed), Wiley (Interscience), New York, USA, 2, 215-227

Do UH, Sprecher H (1975) Studies on the substrate specificity of fatty acid $\Delta 5$ desaturase by use of methyl-branched isomers of eicosa-8, 11, 14-trienoic acid and the metabolism of these acids in rat liver. Arch Biochem Biophys 171, 597-608

Driss F, Darcet $P$, Delhaye N, Mendy F (1988) Effect of eicosapentaenoic acid on RBC filterability and fattyacid composition. Clin Hemorheol 8, 679-685

Eck MG, Wynn JO, Carter WJ, Faas FH (1979) Fattyacid desaturation in experimental diabetes mellitus. Diabetes 28, 479-485

El Boustani S, Causse JE, Descomps B, Monnier L, Mendy F, Crastes de Paulet A (1989) Direct in vivo characterization of delta-5 desaturase activity in humans by deuterium labeling: effect of insulin. Metabolism 38, 315-321

Emken EA (1984) Nutrition and biochemistry of trans and positional fatty-acid isomers in hydrogenated oils. Ann Rev Nutr 4, 339-376

Faas FH, Carter WJ (1982) Fatty-acid desaturation and microsomal lipid fatty acid composition in experimental hyperthyroidism. Biochem J 207, 29-35

Friedmann N, Gelhorn A, Berjamin W (1966) Synthesis of arachidonic acid from linoleic acid in vivo in diabetic rats. Israel J Med Sci 2, 677-682

Garda HA, Brenner RR (1985) in vitro modification of cholesterol content of rat liver microsomes. Effects upon membrane 'fluidity' and activation of glucose6-phosphatase and fatty acid desaturation and synthesis. Biochim Biophys Acta 819, 45-54

Garg ML, Sebo Kova E, Thomson ABR, Clandinin MT (1988a) $\Delta 6$ desaturase activity in liver microsomes of rats fed diets enriched with cholesterol and/or fatty acids. Biochem J 249, 351-356

Garg ML, Thomson ABR, Clandinin MT (1988b) Effect of dietary cholesterol and/or n-3 fatty acids on lipid composition and $\Delta 5$ desaturase activity in rat liver microsomes. J Nutr 118, 661-668 
Gavino GR, Gavino VC (1991) Rat liver outer mitochondrial carnitine palmitoyltransferase activity towards long-chain polyunsaturated fatty acids and their CoA esters. Lipids 26, 266-270

Geiger M, Mohammed BM, Sankarappa S, Sprecher H (1993) Studies to determine if rat liver contains chainlength-specific acyl-CoA 6-desaturases. Biochim Biophys Acta 1170, 137-142

Girault C, Blond JP, Maniongui C, Bézard J (1992) Effect of dietary $\gamma$-linolenic acid on the hepatic $\Delta 6$ desaturase activities in the obese Zucker rat. CR Soc Biol $186,278-282$

Gonzales S, Nervi AM, Peluffo RO (1986) Effect of oestradiol and environmental temperature changes on rat liver $\Delta 6$ microsomal desaturase activity. Lipids $21,440-443$

Green P, Yavin E (1993) Elongation, desaturation and esterification of essential fatty acids by fetal rat brain in vivo. J Lipid Res 34, 2099-2107

Guesnet P, Alessandri JM, Durand G (1993) Métabolisme, fonctions biologiques et importance nutritionnelle des acides gras polyinsaturés. Cah Nutr Diet 28, 19-25

Hagve TA, Christophersen BO (1986) Evidence for peroxisomal retroconversion of adrenic acid (22:4(n-6)) and docosahexaenoic acid $(22: 6(n-3))$ in isolated liver cells. Biochim Biophys Acta 6, 165-173

Halminski MA, Marsh JB, Harrison EH (1991) Differential effects of fish oil, safflower oil and palm oil on fatty acid oxidation and glycerolipid synthesis in rat liver. J Nutr 121, 1554-1561

Hoch Ff (1981) Thyroid hormone control over rat liver membrane lipids. Prog Lipid Res 20, 225-228

Hodgson JM, Wahlquist ML, Boxall JA, Balazs ND (1993) Can linoleic acid contribute to coronary artery disease? Am J Clin Nutr 58, 228-234

Holman RT (1964) Nutritional and metabolic interrelationships between fatty acids. Fed Proc Fed Am Soc Exp Biol 23, 1062-1067

Holman RT (1970) Essential fatty acid deficiency. Prog Chem Fats Lipids 9, 275-348

Holman RT, Smythe L, Johnson S (1979) Effect of sex and age on fatty acid composition of human serum lipids. Am J Clin Nutr 32, 2390-2399

Holman RT, Johnson SB, Hatch TF (1982) A case of human linolenic acid deficiency involving neurological abnormalities. Am J Clin Nutr 35, 617-623

Høy CE, Holman G, Kaur N, Byrjalsen I, Kirstein D (1983) Acyl group distribution in tissue lipids of rats fed evening primrose oil ( $\gamma$-linolenic plus tinoleic acid) or soybean oil ( $\alpha$-inolenic plus linoleic acid). Lipids 18, 760-771

Jones PJH, Pencharz PB, Clandinin MT (1985) Whole body oxidation of dietary fatty acids: implication for energy utilization. Am J Clin Nutr 42, 469-777

Kinkela T, Bézard J (1993) Les lipides de quelques produits alimentaires congolais. Sci Alim 13, 567-575
Kinsella JE (1991) $\alpha$-Linolenic acid: functions and effects on linoleic acid metabolism and eicosanoid-mediated reactions. In: Advances in Food and Nutrition Research (JE Kinsella, ed) Academic Press, San Diego, USA, 35, 1-184

Kinsella JE, Bruckner G; Mai J, Shimp J (1981) Metabolism of trans-fatty acids with emphasis on the effects of trans, trans-octodecadienoate on lipid composition, essential fatty acids and prostaglandins: an overview. Am J Clin Nutr 34, 2307-2318

Kohout M, Kohoutova B, Heimberg M (1971) The regulation of hepatic triglyceride metabolism by free fatty acids. J Biol Chem 246, 5067-5074

Kuksis A, Marai L (1967) Determination of the complex structure of natural lecithins. Lipids 2, 217-224

Kurata AN, Privett OS (1980) Effect of dietary fatty-acid composition on the biosynthesis of unsaturated fatty acids in rat liver microsomes. Lipids 15, 512-518

Lawson LD, Hughes BG (1988a) Triacylglycerol structure of plant and fungal oils containing $\gamma$-linolenic acid. Lipids 23, 313-317

Lawson LD, Hughes BG (1988b) Human absorption of fish oil fatty acids as triacylglycerols, free acids or ethyl esters. Biochem Biophys Res. Commun 152, 326-335

Lawson LD, Hughes BG (1988c) Absorption of eicosapentaenoic acid and docosahexaenoic acid from fish oil triacylglycerols or fish oil ethyl esters co-ingested with a high-fat meal. Biochem Biophys Res Commun $156,960-963$

Lee C-J, Sprecher $H$ (1971) An in vitro study of the effects of dietary alteration and fasting on the desaturation of palmitic, stearic, eicosa-8, 11- dienoic acid and eicosa-8, 11, 14-trienoic acid. Biochim Biophys Acta 248, 180-185

Leikin Al, Brenner RR (1987) Cholesterol-induced microsomal changes modulate desaturase activities. Biochim Biophys Acta 922, 294-303

Leikin Al, Brenner RR (1989) Microsomal $\Delta 5$ desaturation of eicosa-8, 11, 14-trienoic acid is activated by a cytosolic fraction. Lipids 24, 101-104

Lemarchal $P$ (1989) La régulation hormonale et nutritionnelle des desaturases. Cah Nutr Diet 24, 99-106

Lemarchal P, Bourre JM, Darcet $P$ et al (1992) Apports nutritionnels conseillés en acides gras essentiels. In: Apports Nutritionnels Conseillés pour la Population Française ( $\mathrm{H}$ Dupin, J Abraham, I Giachetti, eds), 2nd edition, Lavoisier, Paris, France, 74-81

Leyton J, Drury PJ, Crawford MA (1987) Differential oxidation of saturated and unsaturated fatty acids in vivo in the rat. Br J Nutr 57, 383-393

Litchfield C (1972) Analysis of Triglycerides. Academic Press, New York, London, UK, 233-264

Lowe JB, Sachettini JC, Laposata M, McQuillan JJ, Gordon Jl (1987) Expression of rat intestinal fatty acid binding protein in Escherischia Coli. J Biol Chem 262, 5931-5937 
Lyman RL (1971) Endocrine influences on the metabolism of polyunsaturated fatty acids. In: Progress in the Chemistry of Fats and other Lipids (RT Holman, ed), Pergamon Press, Oxford, 193-230

Mahfouz MM, Smith TL, Kummerow FA (1984) Effect of dietary fats on desaturase activities and the biosynthesis of fatty acids in rat liver microsomes. Lipids 19, 214-222

Mandon EC, De Gomez Dumm INT, Brenner RR (1986) Effect of epinephrine on the oxidative desaturation of fatty acids in the rat adrenal gland. Lipids 21, 401-404

Maniongui C, Gresti J, Bugaut M, Gauthier S, Bézard J (1991) Determination of bovine butterfat triacylglycerols by reversed-phase liquid chromatography and gas chromatography. J Chromatogr 543, 81-103

Maniongui C, Blond JP, Ulmann L, Durand G, Poisson JP, Bézard J (1993) Age-related changes in $\Delta 6$ and $\Delta 5$ desaturase activities in rat liver microsomes. Lipids 28, 291-297

Marcel YL, Christiansen K, Hoiman RT (1968) The preferred metabolic pathway from linoleic acid to arachidonic acid in vitro. Biochim Biophys Acta 164, 2534

Martin JC, Bougnoux P, Fignon A et al (1993) Dependence of human milk essential fatty acids on adipose stores during lactation. Am J Clin Nutr 58, 653659

Mercuri O, Peluffo RO, Brenner RR (1966) Depression of microsomal desaturation of linoleic to gammalinolenic acid in the alloxan-diabetic rat. Biochim Biophys Acta 116, 409-411

Mercuri O, Peluffo RO, Brenner RR (1967) Effect of insulin on the oxidative desaturation of alphalinolenic, oleic and palmitic acids. Lipids 2, 284-285

Mimouni V, Poisson JP (1990) Spontaneous diabetes in BB rats: evidence for insulin dependent liver microsomal $\Delta 6$ and $\Delta 5$ desaturase activities. Horm Metab Res 22, 405-407

Mimouni V, Christiansen EN, Blond JP, Ulmann L, Poisson JP, Bézard J (1991) Elongation and desaturation of arachidonic and eicosapentaenoic acids in rat liver. Effect of clofibrate feeding. Biochim Biophys Acta 1086, 349-353

Mimouni V, Narce M, Poisson JP (1992) Evidence for insulin-dependent hepatic microsomal $\gamma$-linolenic acid chain elongation in spontaneously diabetic Wistar BB rats. Biochim Biophys Acta 1133, 187-192

Mimouni V, Narce M, Huang YS, Horrobin DF, Poisson JP (1994) Adrenic acid $\Delta 4$-desaturation and fatty acid composition in liver microsomes of spontaneously diabetic Wistar BB rats. Prost Leuk EFA 50 , 43-47

Narce M, Poisson JP, Belleville J, Chanussot B (1988) Time-course effects of protein malnutrition on hepatic fatty acid $\Delta 6$ and $\Delta 5$ desaturation in the growing rat. Br J Nutr 60, 389-402

Narce M, Mimouni V, Poisson JP (1992) Effect of sodium loading $(3 \% \mathrm{NaCl})$ on arachidonic acid biosynthe- sis in rat liver microsomes. Prost Leuk EFA 47, 193197

Naughton JM (1981) Supply of polyenic fatty acids to the mammalian brain. The ease of conversion of the short-chain essential fatty acids to their longer chain polyunsaturated metabolites in liver, brain, placenta and blood. Int J Biochem 13, 21-32

Neison GJ, Ackman RG (1988) Absorption and transport of fat in mammals with emphasis on $n-3$ polyunsaturated fatty acids. Lipids 23, 1005-1014

Nervi AM, Catala A, Brenner RR, Peluffo RO (1975) Dietary and hormone effects upon the activity of 'soluble' protein and particulate fraction of fatty-acid desaturation synthesis of rat liver microsomes. Lipids 10, 348-352

Nervi AM, Peluffo RO, Brenner, RR, Leikin Al (1980) Effect of ethanol administration on fatty-acid desaturation. Lipids 15, 263-268

Neuringer M, Anderson GJ, Connor WE (1988) The essentiality of $n-3$ fatty acids for the development and function of the retina and brain. Ann Rev Nutr 8 , 517-541

Ong N, Bézard J, Lecerf J (1977) Incorporation and metabolic conversion of erucic acid in various tissues of the rat in short-term experiments. Lipids 12 , 563-569

Osmundsen H, Thomassen MS, Hiltunen JK, Berge RK (1987) Physiological role of peroxisomal $\beta$-oxidation. In: Peroxisomes in Biology and Medicine (MD Fahimi, H Sies, eds), Springer-Verlag, Berlin, France, 152-165

Osmundsen H, Bremer J, Pedersen Jl (1991) Metabolic aspects of peroxisomal $\beta$-oxidation. Biochim Biophys Acta 1085, 141-158

Pascaud M, Strouve-Vallet $C$ (1985) Desaturation of ${ }^{14} \mathrm{C}$ linoleic acid by the rat fetus. Ann Nutr Metab $29,63-64$

Peluffo RO, Brenner RR (1974) Influence of dietary protein on 6 and 9 desaturation of fatty acids in rats of different ages and in different seasons. $J$ Nutr 104 , 894-900

Periago JL, Pita ML, Sanchez del Castillo MA, Caamano $G$, Suarez MD (1989) Changes in lipid composition of liver microsomes and fatty acyl-CoA desaturase activities induced by medium-chain triglyceride feeding. Lipids $24,383-388$

Poisson JP, Cunnane SC (1991) Long-chain fatty-acid metabolism in fasting and diabetes: relation between altered desaturase activity and fatty acid composition. $J$ Nutr Biochem 2, 60-70

Poisson JP, Lemarchal P, Blond JP, Lecerf J, Mendy F (1978) Influence du diabete alloxanique sur la conversion des acides linoléique et gammalinolénique $\left(1^{-14} \mathrm{C}\right)$ en acide arachidonique chez le rat in vivo. Diabete Metabol 4, 39-45

Poisson JP, Dupuy RP, Sarda P et al (1993a) Evidence that liver microsomes of human neonates desaturate essential fatty acids. Biochim Biophys Acta 1167 , 109-113 
Poisson JP, Huang YS, Mills DE et al (1993b) Effect of salt loading and spontaneous hypertension on in vitro metabolism of $[1-14 \mathrm{C}]$ linoleic acid and $\left[2-{ }^{-14} \mathrm{C}\right]$ dihomo- $\gamma$-linolenic acids. Biochem Med Metabol Biol $49,57-66$

Purvis JM, Clandinin MT, Hacker RR (1982) Fatty-acid accretion during perinatal brain growth in the pig: a model for fatty-acid accretion in human brain. Comp Biochem Physiol B Comp Biochem 72, 195-203

Ransac S, Rogalska E, Gargouri Y, Deveer AMTJ, Paltauf $F$, de Haas GH, Verger R (1990) Stereoselectivity of lipases. I. Hydrolysis of enantiomeric glyceride analogues by gastric and pancreatic lipases, a kinetic study using the monomolecular film technique. J Biol Chem 265, 20263-20270

Ravel D, Chambaz J, Pepin D, Manier MC, Bereziat G (1985) Essential fatty-acid interconversion during gestation in the rat. Biochim Biophys Acta 833, 161-164

Reubsaet FAG, Veerkamp JH, Trijbels JMF, Monnens $\mathrm{LAH}$ (1989) Total and peroxisomal oxidation of various saturated and unsaturated fatty acids in rat liver, heart and $M$ quadriceps. Lipids 24, 945-950

Rogalska E, Ransac S, Verger R (1990) Stereoselectivity of lipases. II. Stereoselective hydrolysis of triglycerides by gastric and pancreatic lipases. $J$ Biol Chem 265, 20271-20276

Rosenthal MD, Whitehurst MC (1983) Selective effects of isomeric cis and trans-fatty acids on fatty acyl $\Delta 9$ and $\Delta 6$ desaturation by human skin fibroblasts. Biochim Biophys Acta 753, 450-459

Rosenthal MD, Doloresco MA (1984) The effects of trans-fatty acids on fatty acyl desaturation by human skin fibroblasts. Lipids $19,869-874$

Satomi S, Matsuda I (1973) Microsomal desaturation of linoleic acid into $\gamma$-linolenic acid in livers of fetal, suckling and pregnant rats. Biol Neonate 22, 1-8

Schulz H (1991) Beta oxidation of fatty acids. Biochim Biophys Acta 1081, 109-120

Scott B, Bazan N (1989) Membrane docosahexaenoate is supplied in the developing brain and retina by the liver. Proc Natl Acad Sci USA 86, 2903-2908

Semporé G, Bézard J (1991) Determination of molecular species of oil triacylglycerols by reversed-phase and chiral-phase high-performance liquid chromatography. J Am Oil Chem Soc 68, 702-709

Shand $\mathrm{JH}$, Noble RC (1981) The metabolism of 18:0 and $18: 2(n-6)$ by the ovine placenta at 120 and 150 days of gestation. Lipids $16,68-71$

Singh H, Derwas N, Poulos A (1987) Very long-chain fatty-acid $\beta$-oxidation by rat liver mitochondria and peroxisomes. Arch Biochem Biophys 259, 382-390

Spector AA, Moore SA (1992) Role of the cerebromicrovascular endothelium and astrocytes in supplying docosahexaenoic acid to the brain. In: Essential Fatty Acids and Eicosanoids (A Sinclair, R Gibson, eds), Am Oil Chem Soc, Champaign, IL, USA, 100103

Sprecher H (1981) Biochemistry of essential fatty acids. Prog Lipid Res 20, 13-24

Sprecher H (1989) Interactions between metabolism of $\mathrm{n}-6$ and $\mathrm{n}-3$ fatty acids. J Intern Med 225, 5-11

Thomson ABR, Keelan M, Garg ML, Clandinin MT (1989) Intestinal aspects of lipid absorption: review. Can J Physiol Pharmacol 67, 179-191

Uauy R, Birch E, Birch D, Periano P (1992) Visual and brain function measurements in studies of $n-3$ fatty acid requirements of infants. J Pediatr 120, 168180

Vamecq J, Vallee J, Lechêne de la Porte P et al (1993) Effects of various $n-3 / n-6$ fatty-acid ratio contents of high fat diets on rat liver and heart peroxisomal and mitochondrial $\beta$-oxidation. Biochim Biophys Acta 1170, 151-156

Vergroesen AJ, Crawtord M (1989) The Role of Fats in Human Nutrition. Academic Press, San Diego, CA, USA

Vericel E, Croset M, Sedivy P, Courpron P, Dechavanne $M$, Lagarde $M$ (1988) Platelets and aging. I. Aggregation, arachidonate metabolism and antioxidant status. Thromb Res 49, 331-342

Voss A, Reinhart M, Sankarappa S, Sprecher H (1991) The metabolism of $7,10,13,16,19$-docosapentaenoic acid to $4,7,10,13,16,19$-docosahexaenoic acid in rat liver is independent of a $\Delta 4$ desaturase. $J$ Biol Chem 266, 19995-20000

Wang DL, Reitz RC (1983) Ethanol ingestion and polyunsaturated fatty acids: effects on the acyl-CoA desaturases. Alcoh Clin Exp Res 7, 220-226

Willumsen N, Skorve J, Hexeberg S, Rustan AC, Berge RK (1993) The hypotriglyceridemic effect of eicosapentaenoic acid in rats is reflected in increased mitochondrial fatty acid oxidation followed by diminished lipogenesis. Lipids 28, 683-690

Yang LY, Kuksis A, Myher JJ (1989) Lumen hydrolysis of menhaden and rapeseed oils and their fatty acid methyl and ethyl esters in the rat. Biochem Cell Biol 67, 192-204

Yurkowski M, Brockerhoff H (1966) Fatty acid distribution in triglycerides determined by deacylation with methyl bromide. Biochim Biophys Acta 123, 55-59

Zevenberger JL, Houtsmuller UMT (1989) Effect of dietary fats on linoleic acid metabolism. A radiolabel study. Biochim Biophys Acta 1002, 312-323

Zimmermann T, Winkler L, Möller V, Schubert H, Goetze $E$ (1979) Synthesis of arachidonic acid in the human placenta in vitro. Biol Neonate 35, 209-212 